\title{
School Segregation and the Identification of Tipping Behavior
}

\author{
Gregorio Caetano and Vikram Maheshri*
}

June 1, 2013

\begin{abstract}
We introduce an empirical framework that synthesizes the key insights of the Schelling model of segregation. Our framework builds upon an established empirical literature in neighborhood choice and can accommodate complex, realistic features that have been absent from prior analyses of tipping and segregation. We implement our approach to study racial segregation in Los Angeles County public schools from 2002-2006 and find substantial heterogeneity in tipping behavior across schools, with most schools featuring two segregated, stable equilibria and a tipping point ranging from 15-85\% minority share. We discuss extensions to our analysis by considering alternative, more general specifications of segregation. JEL Codes: I.20, J.15
\end{abstract}

\section{Introduction}

Models of social interaction feature agents who have preferences over standard (private) amenities and social amenities. Social amenities differ from private amenities in that choices made by one agent affect only the social amenities for other agents and not the private amenities. In the case of school choice, a student's peer group is a social amenity to prospective parents since other parents' enrollment decisions may influence their children's schooling outcomes through peer effects, whereas the facilities of a school, which are unaffected by other parents' decisions, are private amenities. The Schelling model ${ }^{1}$ of segregation concisely explains how interactions between agents which arise from the presence of social amenities may lead to the aggregate phenomena of school or neighborhood segregation and tipping behavior. If, for example, white parents have a sufficiently stronger preference for white peers relative to minority parents, then there exists a threshold minority share above

\footnotetext{
${ }^{*}$ University of Rochester and University of Houston. We thank Carolina Caetano, David Card, Willa Friedman, Tasos Kalandrakis, Joshua Kinsler, Romans Pancs, Jesse Rothstein and various conference and seminar participants for their helpful comments and suggestions. We also thank Yusuke Jinnai and Daniel Ringo for valuable research assistance. All errors are our own.

${ }^{1}$ We use the phrase "Schelling model" to refer to the model of segregation developed by Schelling in a series of papers (Schelling $(1969,1971,2006))$ in which individuals with myopic preferences over their peer group iteratively sort into neighborhoods.
} 
which a school will "tip" towards a stable equilibrium with a greater share of minority students and below which a school will tip towards a stable equilibrium with a lower share of minority students. This threshold in the social amenity (minority share of enrollment) is commonly referred to as a tipping point, and it represents an unstable equilibrium as even a slight perturbation in the level of the social amenity around this point may lead to very different demographic outcomes. ${ }^{2}$

Despite considerable theoretical developments to the Schelling model (e.g. Becker and Murphy (2000); Pancs and Vriend (2007); Zhang (2009)), there have been relatively few empirical developments in implementing this model to identify tipping behavior using observational data. An important reason for this disparity is the fact that the Schelling model obtains a concise explanation for segregation by assuming individual agents behave according to some plausible heuristics. Although this approach is theoretically appealing in its simplicity, this indirect specification of individual preferences is not amenable to the traditional empirical tools that have been developed to analyze preferences and equilibria in models of school and neighborhood choice beginning with McFadden (1973) (e.g., Bayer, McMillan and Rueben (2004), Bayer and Timmins (2005) and Bayer, Ferreira and McMillan (2007)). At the same time, current empirical models of school and neighborhood choice may not be appropriate for analyzing tipping behavior because such models tend to assume that households' choices are observed in equilibrium, i.e., in the absence of further shocks the racial composition of schools/neighborhoods will remain fixed. This assumption stands in contradiction to a central insight of the Schelling model that at any given point, schools and neighborhoods may be observed in the process of tipping - in disequilibrium - rather than already having reached a stable, long run equilibrium. ${ }^{3}$

Recently, Card, Mas and Rothstein (2008a) have circumvented these issues with a reducedform approach to identify tipping points in neighborhoods and schools as thresholds around which the flows of both Whites and minorities are qualitatively different. This is motivated by the fact that if the share of minority households (students) in a neighborhood (school) exceeds a tipping point, then it will experience relative outflows of White households, and if the share of minority households (students) in a neighborhood (school) falls short of a tipping point, it will experience the opposite. ${ }^{4}$ However, as we argue below, any such quasi-experimental identification strategy relies on the assumption that all schools or neighborhoods possess a common, fixed tipping point, which is generally invalid if schools or neighborhoods offer different or changing levels of private amenities (e.g., teachers, facilities, location). ${ }^{5}$ As a motivating example, we present the racial

\footnotetext{
${ }^{2}$ Other context-specific models of social interactions that may feature multiple equilibria are models of herding (Banerjee (1992)), technological adoption (Jackson and Yariv (2006)), and collective action (Ostrom (2000)).

${ }^{3}$ Schelling (1971) analyzes in detail trajectories of the composition of stylized neighborhoods that are potentially out of equilibrium.

${ }^{4}$ Pryor (1971) conducts a similar empirical exercise using a related approach.

${ }^{5}$ Easterly (2009) takes an alternative reduced form approach to identifying tipping behavior, but that approach also relies on the assumption that all neighborhoods possess a common, fixed tipping point.
} 
composition of two Los Angeles County schools over time in figure 1. Each school starts from a roughly equal composition of White and Hispanic students, but starting in 1990, their compositions evolve in different directions. Gardner Street Elementary becomes a predominantly White school while Fulbright Avenue Elementary becomes a predominantly Hispanic school. This disparity is inconsistent with the assumption that these two schools, separated by less than 15 miles, possess common, fixed tipping points.

In this paper, we provide empirical micro-foundations to the Schelling model by building upon the literature on neighborhood choice (e.g., Bayer and Timmins (2005) and Bayer and McMillan (2010)) and offer a novel empirical framework for the analysis of tipping behavior. ${ }^{6}$ Unlike the quasi-experimental identification strategies that have been proposed, our framework accommodates heterogeneity in tipping behavior as well as more complex, realistic features of the tipping process. Moreover, we depart from the literature on neighborhood choice by allowing for individuals' choices to be observed out of equilibrium. This is an empirically important feature, as the observed enrollment dynamics displayed in figure 1 are indicative of adjustment paths to new equilibria.

We identify tipping behavior in a model of public school segregation in two steps: we first use data on school choices to estimate parents' preferences for the relevant social amenity of schools - their racial composition - which are then used in a simulation procedure to uncover tipping behavior in the aggregate. More precisely, in the first step we estimate the partial effects of the social amenity on the schooling demands for White and minority parents explicitly allowing for heterogeneity in the preferences of each group for both private and social amenities. ${ }^{7}$ These partial effects are identified with instrumental variables adapted from Card (2001). In the second step, we use these estimates to simulate the implied enrollment of both groups within a school for different counterfactual racial compositions of that school's enrollment. For any counterfactual level of the share of minority students in a school in a given year, we compute the ensuing share of minority students that is implied under this counterfactual by allowing parents to re-sort holding all other school amenities constant. We can then recover the unique tipping points and stable equilibria for each school in each year from the simulated schedule of the implied share of minority students. ${ }^{8}$

\footnotetext{
${ }^{6}$ As discussed in Bayer and Timmins (2005) and Bayer and Timmins (2007), one main difference between the literature upon which this paper builds and the discrete choice social interactions literature (e.g., Brock and Durlauf (2001a), Brock and Durlauf (2001b), Blume and Durlauf (2003)) is that the former literature explicitly includes unobservable school amenities that are correlated across individuals. Such unobservables are known to be empirically relevant, particularly to locational choice (Bayer, Ferreira and McMillan (2007) and Caetano (2012)). Because of this difference, the economic environments where these two literatures are applicable are distinct in general. For instance, in the discrete choice social interactions literature, the number of choices is fixed and is often binary, whereas in the literature on school and neighborhood choice the number of options needs to be large as asymptotic results are built on this number going to infinity.

${ }^{7}$ Ioannides and Zabel (2008) estimate households' preferences for a variety of other social amenities in a nested model of neighborhood and house choice.

${ }^{8}$ Bayer and Timmins (2005) present a different simulation technique to identify multiple equilibria in the context of social interactions under the assumption that choices are observed in equilibrium. Bayer and McMillan (2010) estimate an equilibrium model of school choice and provide a simulation technique to estimate measures of school competition,
} 
Unlike previous empirical approaches, our framework allows us to identify for each school and year the full trajectory of tipping behavior in the absence of external shocks. We argue that knowledge of this trajectory (which includes the existence and locations of tipping points and stable equilibria) is crucial to inform any policy that aims to impact school segregation. ${ }^{9}$ Moreover, our framework can accommodate techniques from the well established empirical literature on school and neighborhood choice to incorporate complex features that have not yet been considered in the context of tipping behavior.

Racial segregation is exhibited predominantly in schools and neighborhoods. These settings are closely related for two reasons. First, school and neighborhood choices are made concurrently, and each decision impacts the other decision. Attributes of local schools influence the prices and other characteristics of neighborhoods (e.g., Black (1999); Black and Machin (2011)). At the same time, neighborhood attributes affect the quality and other characteristics of local schools (e.g., Vartanian and Gleason (1999)). Second, the social amenity in a model of school segregation (the racial composition of students' prospective peer group) is inherently related to the corresponding social amenity in a model of neighborhood segregation.

We choose to illustrate our empirical method in the context of school segregation because tipping behavior is a dynamic adjustment process, and the analysis of this process requires relatively high frequency data. Public schools are required by federal law to report the racial composition of their enrollment annually, whereas the racial composition of neighborhoods is only available in the decennial Census. As such, we follow a long empirical and theoretical literature that has analyzed causes of school segregation (Echenique, Fryer Jr and Kaufman (2006); Frankel and Volij (2011)) and effects of school segregation (Jackson (2009); Boustan (2012); Billings, Deming and Rockoff (2012)) and has established school segregation as an important topic in its own right. Nevertheless, we stress that our method can be directly implemented to analyze neighborhood segregation if high frequency neighborhood data are available. Moreover, our results in this paper indirectly shed light on the process of neighborhood segregation to the extent that the racial composition of neighborhoods can be proxied by the racial composition of public schools. ${ }^{10}$

We perform our analysis on a sample of all students enrolled in public schools in LA County

but they do not consider social interactions. In a computational study of residential segregation, Bruch and Mare (2006) simulate flows of White and minority residents between neighborhoods under a variety of assumptions, but they do not empirically identify tipping points or stable equilibria.

${ }^{9}$ Knowledge of the locations of both the stable equilibria and tipping points are crucial for policymakers seeking to manipulate current and future levels of segregation. The short-run trend in the racial composition of a school is determined by its current racial composition relative to its tipping point. In the long run, the expected racial composition of a school is determined instead by the locations of its stable equilibria. We discuss in detail how our framework can be used to assess the short-run and long-run impacts of policies on the racial composition of schools.

${ }^{10} \mathrm{We}$ also choose to model school choice rather than neighborhood choice because the timing of the decision (annually) is clearer. In the case of neighborhood choice, households moving at the beginning of a calendar year may observe different minority shares of neighborhoods than households moving at the end of the year. In contrast, the minority shares of schools are less likely to vary within the academic year. 
from 2001-2006 and find that racial segregation and race based tipping is a widespread and diverse phenomenon. Many schools feature a tipping point in a given year, and these tipping points range from a minority share of $15 \%$ to a minority share of $85 \%{ }^{11}$ In addition, most schools possess a stable, segregated equilibrium with a minority share in excess of $80 \%$, and a similar proportion of schools possess a stable, segregated equilibrium with a minority share less than $20 \%$. There is also heterogeneity in the locations of stable equilibria across schools but less heterogeneity in tipping behavior over time.

In order to further explore the process of school segregation and to highlight the strengths of our framework, we extend our analysis in three directions. First, we allow parents' demand for schooling to vary non-linearly in the social amenity, which allows for the existence of more than one tipping point and more than two stable equilibria. Second, we allow parents to possess heterogeneous preferences for multiple social amenities, namely the share of Black enrollment and the share of Hispanic enrollment in a school. Third, we explore the extent to which an inelastic supply of schooling would affect the tipping behavior. We measure the relevance of each of these extensions by comparing the actual minority shares of school enrollments observed in 2007 to the out of sample predictions of minority shares of school enrollments made using various estimation and simulation procedures. In a baseline specification of linear demand with elastically supplied schooling, we find that we are able to predict out of sample minority shares of school enrollments to roughly 6 percentage points accuracy on average using our approach; both allowing for a perfectly inelastic supply and allowing for parents to possess heterogeneous preferences for Black enrollment and Hispanic enrollment result in small improvements in accuracy.

Although the data that we use in our analysis is as least as rich as the data used in the previous reduced-form analyses of tipping behavior, ${ }^{12}$ our approach suggests the need for a more conservative view of the state of the art on this topic, as better data is necessary for a more complete analysis of tipping behavior. ${ }^{13}$ Nevertheless, we believe that the application in this paper constitutes a considerable innovation in the empirical analysis of school segregation in particular and of tipping behavior in general. Importantly, the approach developed in this paper can serve as a platform to accommodate these and other features of social interactions with the availability of better data.

The remainder of the paper is organized as follows. In section 2, we briefly discuss the Schelling model of segregation to highlight the inherent challenges in identifying tipping points and stable

\footnotetext{
${ }^{11}$ We refer to all non-White and White Hispanic parents and students as minorities in spite of the fact they constitute more than half of the public school population in LA County.

${ }^{12}$ For instance, Card, Mas and Rothstein (2008a) use data at the race-neighborhood-decade level, while we use data at the race-school-year level.

${ }^{13}$ For instance, due to a lack of data we are unable to allow for parents to bear moving costs when switching schools, and we are unable to estimate tipping behavior across race-income groups, which we recognize would enrich our empirical analysis. To our knowledge neither of these features have been added to or discussed in detail in a model of segregation before. We offer a detailed discussion of the theoretical and empirical implications of these data shortcomings in appendix A.2, with the intention of advancing the discussion on the topic.
} 
equilibria. In section 3, we present a two stage empirical strategy that explicitly addresses these challenges through estimation and simulation. In section 4, we describe our data set and present baseline empirical results. In section 5 we show how the results change when we relax some assumptions of our empirical model to illustrate how our method can be adapted to analyze more complex, realistic social interaction processes. We conclude by highlighting some directions for future research.

\section{Identification of Tipping Points and Stable Equilibria}

The seminal Schelling (1969) model of segregation and its successors share two key features that have important theoretical and empirical implications for tipping behavior. First, for tipping to occur, agents from different subgroups must have different preferences for the racial composition of schools. ${ }^{14}$ This difference in preferences is necessary (but insufficient) to generate tipping behavior. Second, since tipping is characterized as a dynamic adjustment process, there must exist some friction that ensures that agents do not always immediately take long run equilibrium actions (i.e., the full system has not always reached a stable equilibrium). ${ }^{15}$ In the Schelling model, this friction arises because agents are cast as myopic decision makers. ${ }^{16}$

The Schelling model differs from many standard economic models in that it describes the aggregate phenomenon of segregation in a framework in which individual agents make decisions according to simple heuristics. Becker and Murphy (2000) offer an alternative representation of the Schelling model that is instead based upon the standard economic primitives of preferences for peer groups and demands for housing (or, as in our case, schooling). We motivate the empirical challenges in identifying tipping points and stable equilibria with a simplified model of segregation in this vein. Suppose there are two groups of parents indexed by $r$, where $r=W$ if the parent is White and $r=M$ if the parent is a minority. We assume that each parent has a single child of their own race. In the beginning of each period, parents choose a school for their child to attend. Parents observe a set of amenities for each school $j$ : a social amenity $s_{j}$, which represents the minority share in the school, and a vector of other amenities $X_{j}$, which may include other characteristics of the school,

\footnotetext{
${ }^{14}$ Zhang (2009) generalizes Schelling's model and shows that even when individuals have a preference for integration in the aggregate, a slight difference in the preferences of two groups for the social amenity can still lead to fully segregated equilibria.

${ }^{15}$ Although moving costs are relevant to any analysis of school or neighborhood choice, their existence alone does not guarantee that equilibrium is reached gradually rather than instantaneously. Feasible methods to estimate dynamic discrete choice models with many choice alternatives and a large state space have only recently been developed (Bayer et al. (2011); Caetano (2012)). Given our data constraints, we implement our empirical approach with a zero moving cost assumption. With richer school choice data, our empirical approach could be extended to accommodate moving costs. We provide further detailed discussion on this topic in appendix A.2.

${ }^{16}$ In addition to the Schelling model, myopia is assumed in several spatial models of learning in urban economics and economic geography (e.g., Maskell and Malmberg (2007)). Kandori, Mailath and Rob (1993) justify myopia in models of social interactions if agents have difficulty conceptualizing the best responses of others. Levinthal and March (1993) provide an overview of the theoretical and empirical literature on myopia in learning.
} 
the (implicit) price of attending the school, and characteristics of competing schools. Parents are myopic; that is, they observe amenities at their levels at end of the previous school year and select their school for the upcoming year without taking into account the simultaneous decisions of other parents. Aggregate parental demand functions can be written as $n_{j}^{r}(s, X)$, which represents the total number of parents of race $r$ who demand to send their child to school $j$. It follows that the resulting minority share in school $j$ in the next period will be

$$
S_{j}\left(s_{j}, X_{j}\right)=\frac{n_{j}^{M}\left(s_{j}, X_{j}\right)}{n_{j}^{W}\left(s_{j}, X_{j}\right)+n_{j}^{M}\left(s_{j}, X_{j}\right)} .
$$

Figure 2a illustrates a theoretical plot of $S_{j}(s)$ for particular demand curves $n_{j}^{W}\left(s, X_{j}\right)$ and $n_{j}^{M}\left(s, X_{j}\right) .{ }^{17}$ Values of $s$ where the curve crosses the 45 degree line (i.e., $\left.S_{j}(s)=s\right)$ are equilibria; for these values of $s$, the minority share of students at the school is not expected to change in the next period in the absence of shocks. A tipping point $s^{\star}$, or unstable equilibrium, is a point that crosses the 45 degree line from below, and a stable equilibrium $s^{\star \star}$ is a point that crosses the 45 degree line from above. ${ }^{18}$ At a stable equilibrium, small deviations of $s$ will result in Whites and minorities re-sorting in such a way that the minority share will return to the stable equilibrium level. At a tipping point, small deviations of $s$ will result in Whites and minorities re-sorting in such a way that the minority share will diverge from the tipping point towards a stable equilibrium.

Empirical identification of tipping points and stable equilibria is complicated by the fact that the demand schedules of the groups may be difficult to recover. The identification is further complicated if parents face a multinomial choice rather than a binary choice, as $X_{j}$ will include not only school $j$ amenities but also the amenities of other schools (including the share of minority students in these schools). However, figure 2a suggests a natural reduced-form approach to identify tipping points without the specification of all relevant demand functions, which has been implemented by Pryor (1971), Card, Mas and Rothstein (2008a) and Pan (2011). We describe this approach, discuss its drawbacks and then propose an alternative identification strategy that does not face such drawbacks.

Suppose $s_{j}$ is observed for two periods, $t$ and $t+1$, in a sample of several schools with a common tipping point $s^{\star}=s_{j}^{\star}$ for all $j$. One could plot $s_{j t+1}$ on $s_{j t}$ for these schools on a single set of axes as in figure 2a. The identification of tipping points is then reduced to finding the point on the x-axis at which the plotted curve crosses the 45 degree line from below.

This identification strategy relies on two strong assumptions. First, all schools in the sample must have a common tipping point at period $t$. This is immediate, as the entire sample of schools

\footnotetext{
${ }^{17}$ For simplicity, we omit the argument $X_{j}$ when referring to the function $S_{j}$.

${ }^{18}$ Points at which the curve $S_{j}(s)$ crosses the 45 degree line from above with a negative slope are not necessarily stable equilibria. For values of $s$ around these points, we will observe oscillating dynamics that can lead to either convergence towards the crossing point or divergence towards a segregated equilibrium depending on the steepness of $S_{j}$. As we do not observe these more complex dynamics in our baseline empirical analysis, we ignore them for simplicity.
} 
is used in order to identify a single point. But to the extent that schools offer different levels of private amenities to their students (i.e., $X_{j} \neq X_{k}$ ), the demand schedules of parents for different schools are not generically the same. It follows that figure $2 \mathrm{a}$ is unique to each school, so in general this assumption will be invalid.

The second assumption underlying this reduced-form identification strategy is that all amenities in $X_{j}$ must remain fixed from periods $t$ to $t+1$. This is immediate, as each point in the plot is an ordered pair $\left(s_{j t}, s_{j t+1}\right)$ that is assumed to reflect an identical school in all respects besides minority share. But $X_{j t} \neq X_{j t+1}$ in general, so $s^{\star}$ and $s^{\star \star}$ are likely to change from $t$ to $t+1$, rendering any fixed point approach that equates shares of minority students in periods $t$ and $t+1$ flawed.

The key empirical takeaway from this discussion is that heterogeneity in tipping behavior is derived from heterogeneity in the levels of private amenities in the schools as opposed to heterogeneity in parental preferences. ${ }^{19}$ Hence, all previous approaches to identify tipping behavior that implicitly assume a common tipping point across any subset of schools also assume that those schools possess identical, fixed private amenities. ${ }^{20}$

In order to avoid these assumptions, we offer a two stage approach to recover tipping behavior in which we essentially construct figure 2a separately for each school and each year. The general idea is as follows: First, we estimate demand schedules $n_{j t}^{W}\left(s, X_{j t}\right)$ and $n_{j t}^{M}\left(s, X_{j t}\right)$ for each school $j$ in each year $t$ allowing for heterogeneity in preferences for all (social and private) amenities across races. We use instrumental variables to identify the causal effects of $s$ on the demands of each race. With estimates of these causal effects, we can simulate $S_{j t}\left(s, X_{j t}\right)$ as a ceteris paribus function of any counterfactual value of the share of minority students in that school in a given year, allowing parents to re-sort across all schools and holding $X_{j t}$ constant; that is, we construct $S_{j t}$ by simulating movements along parents' demand schedules. The simulated function $S_{j t}(s)$ should be interpreted as the minority share that is implied by the counterfactual $s$ in the absence of any shocks. Having identified the entire curve $S_{j t}\left(s, X_{j t}\right)$, it is straightforward to recover unique tipping points and stable equilibria for each school in each year.

\section{Empirical Strategy}

Our empirical strategy is built upon the idea that tipping behavior is ultimately derived from parents' demands for schooling - in particular, their preferences for social amenities. As such, we

\footnotetext{
${ }^{19}$ This point is developed in greater detail in Banzhaf and Walsh (2013).

${ }^{20}$ It is difficult to interpret the discontinuities found in Card, Mas and Rothstein (2008a) as tipping points for two reasons. As the running variable (minority share in the prior period) changes, the unknown point of discontinuity will likely change with it, complicating the interpretation of discontinuities as tipping points. Moreover, in a deviation from standard Schelling models, Card, Mas and Rothstein (2008a) define tipping points as any level of $s$ for which the curve $S_{j}$ is discontinuous (as recognized by Card, Mas and Rothstein (2008a), these are usually referred to as bifurcation points) in order to employ an RDD. In this paper, we use the standard definition of a tipping point, for which an RDD is unavailable as a quasi-experimental analog.
} 
proceed via a two step procedure involving estimation of the causal partial effects of social amenities on race specific demands followed by simulation. In this section, we choose the simplest possible specification of demand that allows for the possibility of tipping behavior in order to illustrate this point most clearly and to highlight the ease with which our approach can be implemented. Not only are the data requirements minimal - we need only data aggregated at the school level, not individual micro data - but the estimation can be carried out by least squares. This basic specification serves as a platform that we can modify to accommodate more complex tipping behavior, which we describe in section 5 .

We note that this specification is substantively equivalent to a static discrete choice framework for estimating demand for schooling (Berry (1994)). In this view, parents make a decision each year of whether or not to enroll their child in public schools in Los Angeles County (as opposed to private schools or schools in other counties), and if so they conduct a full comparison of amenities across all LA County public schools. The associated simulation procedure is mathematically equivalent to the corresponding simulation procedure implied by this discrete choice framework. We discuss these equivalences and how more sophisticated demand estimation procedures can be incorporated in further detail in appendix A.1.

\subsection{Estimating Parental Demand for Schooling}

In year $t, n_{j t}^{r}$ children of race $r$ attend one of $J$ public schools in LA County, so the minority share of students at the school is given by $s_{j t}=n_{j t}^{M} /\left(n_{j t}^{M}+n_{j t}^{W}\right)$. Parents make their enrollment decisions in year $t$ having observed school amenities at the end of year $t-1$. In accordance with the Schelling model, parents do not strategically extrapolate other parents' future enrollment decisions when making their own enrollment decisions, so dynamic adjustment unfolds at a period by period pace. ${ }^{21}$ We specify the log number of students of race $r$ that enroll in school $j$ as

$$
\log n_{j t}^{r}=\beta^{r} s_{j t-1}+X_{j t-1}^{\prime} \phi^{r}+\gamma_{j}^{r}+\alpha_{t}^{r}+\epsilon_{j t}^{r}
$$

where $X_{j t-1}$ is a vector of other year- and school-specific amenities that were observed at the end of the previous year. $\gamma_{j}^{r}$ is a school- and race- level fixed effect, $\alpha_{t}^{r}$ is a race- and year- fixed effect, and the parameters $\beta^{r}$ and $\phi^{r}$ are race-specific parameters that relate school amenities to demand. Equation (2) contains three distinct sources of dynamics. First, the race-year fixed effects $\alpha_{t}^{r}$ account for county- and race- level shocks that include broader demographic changes to LA County and racespecific trends into private school enrollments. Second, the error term $\epsilon_{j t}^{r}$ accounts for race- school-

\footnotetext{
${ }^{21}$ We assume the parents only use information from period $t-1$ when making their decision in period $t$, but this assumption can be weakened with an alternative specification of demand in (2) that includes additional lagged minority share terms and/or time derivatives of minority share. This assumption serves the additional purpose of helping us break the simultaneity problem present in equilibrium choice models with social interactions since $s_{j t-1}$ is not a function of $n_{j t}^{r}$, but $s_{j t}$ is. We discuss the myopia assumption in further detail in appendix A.2.
} 
and year- specific shocks that are unobserved determinants of demand. And third, the specification of $s_{j t-1}$ on the right hand side describes an explicit endogenous relationship between the prior racial composition of schools and current race specific demands for schooling. As described in section 2, this third source of dynamics is exactly the one prescribed by the Schelling model of segregation, therefore our goal is to isolate this source of dynamics from the other sources in order to analyze tipping behavior.

The parameter of interest, $\beta^{r}$, represents the full reduced-form causal effect of $s_{j t-1}$ on $\log$ demand. $\beta^{r}$ need not represent racial preferences per se. It includes parents' preferences for other attributes that are in turn determined by the racial composition of schools. ${ }^{22}$ To be sure, race is not the only social amenity that parents consider. For instance, it is likely that other demographic characteristics of schools are also considered, such as the average income of the parents in the school, or the average level of education of the parents in the school. In order to identify tipping behavior with respect to race, we must include any effect of $s_{j t-1}$ on $\log n_{j t}^{r}$ in our estimate of $\beta^{r}$ including indirect effects through other social amenities. For example, if changes in $s_{j t-1}$ result in changes to school quality in period $t-1$ (if the distribution of student ability depends on race), then the effect of these changes in school quality on $\log n_{j t}^{r}$ must be included in our estimate of $\beta^{r}$. Similarly, if changes in $s_{j t-1}$ result in changes in the average income of peers in period $t-1$ (if the distribution of income depends on race), then the effect of these changes in the average income of peers on $\log n_{j t}^{r}$ must be also included in our estimate of $\beta^{r}$. Thus, ideally in our preferred specification we should not control for any amenities that vary with racial composition (i.e., are post-determined). ${ }^{23}$

Identification of $\beta^{r}$ is complicated by the fact that the minority share of school enrollment is potentially correlated with other unobserved amenities contained in $\epsilon_{j t}^{r}$. To address this concern, we estimate $\beta^{r}$ by two stage least squares (2SLS) using an instrument for $s_{j t-1}$ adapted from Card (2001) and Card (2009) that generates variation in $s_{j t-1}$ that is uncorrelated to any current changes in school amenities. The intuition behind this instrument is analogous to the intuition given in Card (2001). Briefly, we use the counterfactual minority share for a given school in period $t-1$ that would be implied by (plausibly exogenous) historical enrollment patterns at that school and current county wide enrollment trends as an instrument for the actual minority share of enrollment that we observe in period $t-1$.

\footnotetext{
${ }^{22}$ This specification of preferences is in line with recent empirical work on school segregation such as Jackson (2009) and Billings, Deming and Rockoff (2012), and we discuss it in further detail in appendix A.2.

${ }^{23}$ Only the social amenities that are used to stratify demand on the left hand side of equation (2) should be included on the right hand side. If, for instance, enrollment data was available at the race-income level then both racial and income social amenities could be included on the right-rand-side of equation (2), and our approach would identify tipping behavior with respect to both social amenities simultaneously. In section 5.2 we illustrate multidimensional tipping behavior but only with respect to multiple racial groups as enrollment data at the race-income level is unavailable. We provide a detailed discussion of this topic in appendix A.2.
} 
More formally, let $\tau$ represent some fixed year prior to the first year of the sample. ${ }^{24}$ Then

$$
z_{j t-1}=\frac{\frac{n_{j \tau}^{M}}{N_{\tau}^{M}} \cdot N_{t-1}^{M}}{\frac{n_{j \tau}^{M}}{N_{\tau}^{M}} \cdot N_{t-1}^{M}+\frac{n_{j \tau}^{W}}{N_{\tau}^{W}} \cdot N_{t-1}^{W}}
$$

is our instrument for $s_{j t-1}$, where $N_{t-1}^{r}$ is the total number of students of race $r$ in year $t-1$ across all public schools in LA County. The fraction $\frac{n_{j \tau}^{r}}{N_{\tau}^{r}}$ is the proportion of students that historically enrolled in school $j$ in period $\tau$, conditional on having chosen to attend a public school in LA County, hence $\frac{n_{j \tau}^{r}}{N_{\tau}^{r}} \cdot N_{t-1}^{r}$ can be interpreted as the counterfactual number of students of race $r$ enrolled in school $j$ that is implied by the school's historical enrollment pattern in $\tau$ (due to school-specific shocks in $\tau$ ) and the county-wide enrollment trend in $t-1$ (due to county-wide shocks in $t-1$ ). Provided that the county-wide shocks in period $t-1$ are not correlated to school-specific shocks in $t, z_{j t-1}$ will be a valid instrument. To see this, note that the fixed effects $\alpha_{t}^{r}$ and $\gamma_{j}^{r}$ control for all unobserved determinants of school choice that are year-race and school-race specific respectively, so they absorb all county-wide shocks in period $t$ and school-specific amenities that do not vary over the sample period, including any shocks that led students to enroll in school $j$ in period $\tau{ }^{25}$ Thus, $z_{j t-1}$ can be thought of as an exogenous shifter of the supply of students of each race. Because we include year-race fixed effects in equation (2), these exogenous shifts are achieved by transitory shocks that occurred in period $t-1$ but lie dormant in period $t .^{26}$

Intuitively, suppose that there is only one unobserved school amenity, school quality, and Whites value it relatively more than minorities. This implies that $s_{j t-1}$ is endogenous because it is correlated with school quality (i.e., schools of higher unobserved quality will tend to have relatively higher White enrollments and hence lower minority shares). Since we control for school-race fixed effects, the only source of bias in $\beta^{r}$ is students' sorting due to a change in school quality from period $t-2$ to period $t-1$. Because the only source of variation in the instrument $z_{j t-1}$ from period $t-2$ to $t-1$ is at the county level (it does not vary by school), it is not likely to be correlated to the change in school quality from $t-2$ to $t-1$ of that particular school $j$. Thus, unless parents decide to switch to a particular public school $j$ in $t$ from either a public school outside of LA County or a private school because of a transitory change in the relative desirability of that school in $t-1, z_{j t-1}$ will be a valid instrument. ${ }^{27}$

\footnotetext{
${ }^{24}$ In our analysis, we fix $\tau=1999$, but all presented results are robust to different choices of $\tau \in\{1990, \ldots, 1999\}$. The choice of $\tau$ represents a tradeoff between validity and relevance of our instrument. Earlier values of $\tau$ generally correspond to less relevant, but more likely valid instruments. The fact that our results are insensitive to the choice of $\tau$ suggests that we need not worry about this tradeoff in practice.

${ }^{25}$ As a robustness check, we replicated the analysis by including $\log n_{j t-1}^{r}$ as a control instead of $\gamma_{j}^{r}$ and found the same results.

${ }^{26}$ Formally these shocks may not be transitory, as they may be dormant in period $t$ but show up again in later periods; however this is irrelevant to the discussion of whether $z_{j t-1}$ is correlated to $\epsilon_{j t}^{r}$.

${ }^{27}$ To address the concern that large schools might affect the flow of students into or out of LA County, or that private schools close to school $j$ may suffer a negative shock that leads parents to sort into school $j$ more often than
} 
One potential source of endogeneity that deserves particular attention is the unobserved minority share of neighborhoods. In LA County, school allocation is predominantly determined by residential location, although not entirely so. Our instrument directly addresses this issue as it generates variation in the endogenous social amenity only through the sorting of parents with children in public schools. ${ }^{28}$

\subsection{Recovering Tipping Points and Stable Equilibria}

The demand functions estimated from equation (2) can be used to simulate the implied minority share function $S_{j t}(s)$ in an environment in which fixed points of this function can be interpreted as tipping points and stable equilibria. That is, we simulate $S_{j t}(s)$ in the absence of shocks from $t$ to $t+1$. This allows us to identify tipping points and stable equilibria at every period even though school amenities are not necessarily fixed over time. To do so, we first construct the counterfactual demand function

$$
n_{j t}^{r}(s)=\exp \left(\log \left(n_{j t}^{r}\right)+\hat{\beta}^{r}\left(s-s_{j t-1}\right)\right)
$$

which corresponds to the expected number of race $r$ students that would enroll in school $j$ in year $t$ for a given counterfactual value of $s_{j t-1}=s$ (with hats corresponding to estimated parameters). ${ }^{29}$ Importantly, we do not need to estimate demand fully in order to compute the counterfactual demand function; that is, we do not need to account for all determinants of demand provided that our estimates of $\beta^{r}$ are consistent. ${ }^{30}$ It follows that the share of observed total numbers of race $r$ students that would enroll in school $j$ under this counterfactual is given by

$$
\tilde{n}_{j t}^{r}(s)=\frac{n_{j t}^{r}(s)}{\sum_{k} n_{k t}^{r}(s)} \cdot N_{t}^{r}
$$

The calculation in equation (5) ensures that the total student population of LA County remains constant for each level of the counterfactual minority share.

to other public schools in LA, we constructed an alternative instrument as above replacing $N_{t-1}^{r}$ with $N_{t-1,-j}^{r}$ which is the total number of race $r$ students in all LA County public schools except school $j$ in period $t-1$. All results presented were indistinguishable to three decimal points. This is not surprising since the total number of schools is large in our sample $(J=1692)$.

${ }^{28}$ As a robustness check, we estimate race specific parental demands that include ZIP code-year-race fixed effects. We obtain similar results as in specifications with year-race fixed effects, at the expense of larger standard errors. This provides further evidence that school minority share has an important role in school tipping behavior independently of the neighborhood racial composition. However, it may still be the case that neighborhood minority share has an additional distinct effect on tipping behavior. A full, simultaneous analysis of neighborhood and school choice, although necessary in any complete analysis of tipping behavior, is beyond the scope of this paper, as it requires geographically detailed annual data on both school and residential decisions, which is not available.

${ }^{29}$ Note that $n_{j t}^{r}$ represents the actual number of students of each race in the data, while the function $n_{j t}^{r}(s)$ represents the implied number of students of each race for each counterfactual level of the social amenity.

${ }^{30}$ This is a consequence of our assumption that demand is separable in $s_{j t-1}$. 
The implied share of minority students is then defined as

$$
S_{j t}(s)=\frac{\tilde{n}_{j t}^{M}(s)}{\tilde{n}_{j t}^{M}(s)+\tilde{n}_{j t}^{W}(s)}
$$

The numerator of equation (6) is the total number of minority students that would enroll in school $j$ if its minority share was previously $s$, and the denominator is the total enrollment of school $j$ if its minority share was previously $s$. A plot of $S_{j t}$ on $s$ is a natural analog to figure 2a. Each point of the simulated curve $S_{j t}(s)$ corresponds to the implied minority share for school $j$ at time $t$ under the counterfactual assumption that $s_{j t-1}=s .{ }^{31}$ Note that the only source of dynamics that we use to identify $S_{j t}(\cdot)$ is the relationship between demand and $s_{j t-1}$ that is explicitly modeled in equation (2). Because our simulation is performed in the absence of other shocks (i.e., we effectively hold $\alpha_{t}^{r}$ and $\epsilon_{j t}^{r}$ fixed) we can isolate this relationship from the other sources of dynamics described above.

In period $t$, school $j$ possesses either a tipping point or a stable equilibrium at any level of $s$ where $S_{j t}(s)=s$. This equation does not generally possess an analytical solution (Marques and Lima (2010)), so we use a numerical technique to estimate tipping points and stable equilibria. We allow $s$ to take on values ranging from 0 to 1 in increments of 0.01 , and at each value of $s$, we simulate $S_{j t}(s)$ using equation (6). We then plot these simulated shares $S_{j t}$ on $s$ and locate the value(s) of $s$ for which the plot crosses the 45 degree line. A value of $s$ for which the simulated function $S_{j t}$ crosses the 45 degree line from below (i.e., $S_{j t}^{\prime}>1$ ) represents a tipping point $s^{\star}$, and a value of $s$ for which $S$ crosses the 45 degree line from above (i.e., $S_{j t}^{\prime}<1$ ) represents a stable equilibrium $s^{\star \star} \cdot 32$

\subsection{Comparative Statics}

Although closed form representations of tipping points $s_{j t}^{\star}$ and stable equilibria $s_{j t}^{\star \star}$ do not exist, we can exploit the structure of the empirical model in order to derive some useful theoretical predictions that are especially transparent when White parents and minority parents have opposite

\footnotetext{
${ }^{31}$ This simulation procedure can be implemented under many counterfactuals. For example, we may set $s_{j t-1}$ to $s$ without changing the minority shares of other schools, or we may generally allow for the counterfactual minority shares of other schools to change with $s$ in a manner consistent with an estimated model of school supply. In this paper, we simulate enrollments by setting $s_{j t-1}=s$ without changing the minority shares of other schools. We discuss this matter in further detail in section 5.3.

${ }^{32}$ Schools that are observed at off-equilibrium points will not necessarily be observed to converge over time to the corresponding stable equilibrium because the $S$ curve may change over time. For each $z=1,2, \ldots$, the curve may change for the following two reasons: first, there may be future county level shocks $\left(\alpha_{t+z}^{r}\right)$ or school level shocks $\left(\epsilon_{j t+z}^{r}\right)$ which will imply a change in the curve calculated in $t$ in comparison to the curve calculated in $t+z$. Second, as parents endogenously re-sort from off-equilibrium points in other schools $k \neq j$ from $t+z-1$ to $t+z$ because of the tipping mechanism (i.e., according to the curve in period $t+z-1$ ), the curve of school $j$ changes from period $t+z-1$ to $t+z$. As such, our simulation should be interpreted as providing a snapshot of the $S$ curve of each school at period $t$.
} 
preferences over the amenity.

Proposition 1. (Comparative Statics on $X_{j t-1}$ ) An increase (decrease) in any amenity that White parents enjoy and minority parents do not enjoy shifts the simulated curve $S_{j t}$ down (up). The opposite is true of an increase (decrease) in any amenity that minority parents enjoy and White parents do not enjoy.

Proof. Let $\check{\phi}^{r}$ be the scalar coefficient on some particular amenity $x_{j t-1}$ of $X_{j t-1}$. The result follows from differentiating equation (6) with respect to $x_{j t-1}$ and noting that $\frac{\partial \log \left(n_{j t}^{r}\right)}{\partial x_{j t-1}}=\check{\phi}^{r}$.

An increase in the level of an amenity that White parents enjoy relative to minority parents makes that school relatively more attractive to white parents on average, which causes the expected future minority share of enrollment at that school to decrease for any value of $s$. This results in a downward shift of the simulated curve $S_{j t}$ as depicted in figure $2 \mathrm{~b}$. Such a shift affects the locations of tipping points and stable equilibria in a predictable way.

Corollary. Any increase in any amenity $x_{j t-1}$ that White parents enjoy and minority parents do not enjoy shifts the location of the tipping point (if it continues existing) up and shifts the locations of stable equilibria (if they continue existing) down (If $\check{\phi}^{W}>0$ and $\check{\phi}^{M}<0$, then $\frac{\partial s_{j t}^{\star}}{\partial x_{j t-1}}>0$ and $\frac{\partial s_{j t}^{\star \star}}{\partial x_{j t-1}}<0$.) The opposite is true of an increase in any amenity that minority parents enjoy and White parents do not enjoy (If $\check{\phi}^{W}<0$ and $\check{\phi}^{M}>0$, then $\frac{\partial s_{j t}^{\star}}{\partial x_{j t-1}}<0$ and $\frac{\partial s_{j t}^{\star \star}}{\partial x_{j t-1}}>0$.)

In general, a change in the amenity $x_{j t-1}$ will shift the curve $S_{j t}$ even if White and minority parents have similar preferences for the amenity. Hence, heterogeneity in amenities across schools (and within schools over time) implies heterogeneity in tipping behavior and in particular heterogeneity in the locations of tipping points and stable equilibria.

Additionally, this suggests a tool that policymakers may use in order to influence school segregation. With causal estimates of parents' preferences and the simulated curve $S_{j t}$, policymakers can actively adjust the private amenities in school $j$ to affect tipping behavior. By shifting the tipping point, policymakers can reverse the direction of tipping behavior in the short run. They can also shift the relevant stable equilibrium to a more appealing location, affecting the long-run level of segregation. Although under reasonable assumptions we can identify causal estimates of $\beta^{r}$ in our empirical illustration, which permits identification of tipping behavior, our instrumental variables do not permit us to give our estimates of $\phi^{r}$ a causal interpretation. As such, we hesitate to compute any comparative statics on $X_{j t-1}$ using our data. Nevertheless, given that the estimation of preference parameters for private amenities is the objective of a large literature in public 
and urban economics, this literature in combination with our empirical framework may be useful to policymakers. ${ }^{33}$

\section{Data and Results}

\subsection{Sample}

We construct a sample of every public school in Los Angeles County that offered instruction in any grade from kindergarten through 12 th grade for all years between 1999 and $2006 .{ }^{34}$ For each of the 1692 schools in the sample, we obtain grade level enrollment statistics from the Common Core of Data, a public database maintained by the Center for Education Statistics at the US Department of Education. 35

The average minority share in all LA County public schools from 1984-2010 is shown in figure 3. Despite our terminology, the number of minority students enrolled in LA County schools greatly exceeds the number of non-Hispanic white students in all years. In general, there is a small absolute decline in White and Black enrollment, which is accompanied by substantial Hispanic inflows into LA County. ${ }^{36}$ This implies that minority shares will tend to increase in all schools in the absence of school specific shocks, which constitute the plausibly exogenous variation from which we identify $\beta^{r}$.

The Common Core includes only limited demographic data for each school, so we must supplement it with data on school amenities from the California Basic Educational Data System (CBEDS), which is maintained by the California Department of Education. By doing so, we are prevented from using 1984-2010 as our sample period, as data on several school amenities are unavailable before 2000 and after $2006 .^{37}$ Nevertheless, our use of the remaining six year sample period weakens our modeling assumption that parents' preferences for the racial composition of schools (as captured

${ }^{33}$ Black and Machin (2011) provide a recent survey of the literature on estimating preferences for school quality.

\footnotetext{
${ }^{34}$ For our purposes, "year" refers to academic year by registration date, not calendar year. For example, 2007 corresponds to the Fall 2007-Spring 2008 academic year. Only data from 2001-2006 are effectively used in the main analysis of the paper, as enrollment data for 1999 are only used to construct the instrumental variable.

${ }^{35}$ Unfortunately, individual level student data in the state of California is unavailable in restricted or unrestricted formats. Since we only need to identify the partial effect of minority share on aggregated demand for our approach, we do not have to identify demand fully. We discuss this point in further detail in appendix A.2.
}

\footnotetext{
${ }^{36}$ This decline in White enrollment is likely due to declining fertility rates, as total private school enrollment in California remained roughly constant over the sample period. (Source: CBEDS data collection, Educational Demographics, October 2008, and 2008-09 Private School Affidavits.)

${ }^{37}$ We obtain qualitatively similar results when we replicate our analysis over other sub-periods between 1985 and 2010 without including other school amenities. These results are available from the authors upon request.
} 
in the parameters $\beta^{r}$ ) do not change over the sample period. ${ }^{38}$ Summary statistics of the data are presented in table 1. Following our approach the key variable of interest is the minority share in each school, which ranges from $6 \%$ to nearly $100 \%$ with an annual average close to $80 \%$ (for 2006 , we present the distribution of the observed racial composition of schools in figure B.1 in the online appendix).

For each school, we collect the base Academic Performance index (API), an accountability measure devised by the California State Board of Education that is specifically designed to compare overall performance across different schools and within schools over time. The index is a composite of students' performance across multiple content areas based on statewide testing and ranges from 200 to 1000. For the schools in our sample, the average API consistently increased from 648 in 2002 to 715 in 2006, although this falls below the target score of 800 established by the State Board of Education.

We also compute the share of students in each school who are eligible for a free or reduced price lunch under the National School Lunch Program (NSLP). A student qualifies for a free lunch if their family's income is below $130 \%$ of the federal poverty threshold or a reduced price lunch if their family's income ranges from $130 \%$ to $185 \%$ of the federal poverty threshold. Accordingly, this variable is a natural proxy for the average income level of a school's student body. In our sample, approximately $60 \%$ of students meet the eligibility criteria set forth in the NSLP, which is higher than the national eligibility rate of $40 \%$ and the California eligibility rate of $48 \%$ in $2006 .{ }^{39}$ We also proxy for the socioeconomic status of students with the proportion of students whose parents have at least some college education. In our sample, slightly below half of students have a parent with at least some college education.

In addition to the aforementioned social amenities, we also collect data on a variety of private amenities that correspond to school attributes. From CBEDS, we construct various measures of teacher quantity and quality. On average, schools provide one full time equivalent teacher per sixteen students over the sample period, which is nearly identical to the national average. ${ }^{40}$ Approximately $80 \%$ of teachers have bachelors degrees, and the share of teachers with masters degrees increased from $35 \%$ to $42 \%$ over the sample period, both of which are much lower than the national averages of $98 \%$ and $58 \%$ respectively in $2005 .{ }^{41}$ Roughly $40 \%$ of teachers are minorities, which is substantially higher than the national average of $15 \%$ in $2005 .{ }^{42}$ On average, schools offer the equivalent of one full time staff member per one hundred students who is exclusively dedicated to providing English

\footnotetext{
${ }^{38}$ This assumption is consistent with survey findings aggregated in Bobo et al. (2012).

${ }^{39}$ We calculate the national and state eligibility rates from the Common Core.

${ }^{40}$ Source: Digest of Education Statistics, 2010. (2011). U.S. Department of Education, National Center for Education Statistics.

${ }^{41}$ Source: Profile of Teachers in the US, 2011. (2011). US Department of Education, National Center for Education Information.

${ }^{42}$ Source: Profile of Teachers in the US, 2011. (2011). US Department of Education, National Center for Education Information.
} 
language learning support to Spanish speaking students.

We also consider three other private amenities that schools offer. Over our sample period, the number of computers available for each student increases from 0.19 to 0.28 , which is been accompanied by an increase in internet connected computers per student of 0.04 to 0.06 . Computer availability in LA County Schools is roughly equivalent to national averages (one computer for five students in 2000), but internet access lags the national average of one internet connected computer per seven students in 2000. ${ }^{43}$ Finally, the proportion of schools operating on a traditional (i.e., not "year-round") calendar increases from $73 \%$ to $79 \%$ over our sample period. We conclude by noting the considerable variation in the levels of private amenities in our sample, as the standard deviations of these variables ranges from one third of their mean to roughly the mean itself. Such variation indicates potential for heterogeneity in tipping behavior.

\subsection{Baseline Parameter Estimates}

We estimate the parameters of equation (2) under five specifications of parents' demand for schooling and present the results in table 2. In the first specification, we estimate the parameters by OLS. In the remaining specifications, we estimate the parameters by 2SLS using the implied White and minority enrollments described above as instruments. In all specifications, we include school-race fixed effects to control for time invariant school characteristics (e.g., school district, grades of instruction offered, charter/magnet school status) and year-race fixed effects to account for the empirical fact that the set of students in LA County public schools is changing over time. We cluster our standard errors by school and race to account for potential serial correlation of unobserved amenities across years. Coefficients on other amenities are omitted for brevity and are presented in the appendix. To simplify the presentation of our results, we do not distinguish between students in different grades. We find similar results when we estimate race- and grade-specific demands for schooling and school-, grade- and year-specific tipping points and stable equilibria in this and all subsequent sections of the paper. ${ }^{44}$

In the first specification of table 2 , we do not include other observable school amenities and do not correct for endogeneity using instrumental variables. Whites prefer enrolling their children in schools with a lower minority share $\left(\hat{\beta}^{W}<0\right)$, whereas minorities prefer enrolling their children in schools with a higher minority share $\left(\hat{\beta}^{M}>0\right)$, although minorities' racial preferences are moderately less intense than Whites' racial preferences.

In the second specification, we estimate the same parameters as in the first specification, but we correct for endogeneity using instrumental variables. ${ }^{45}$ Two differences emerge between our 2SLS

\footnotetext{
${ }^{43}$ Source: Internet Access in US Public Schools and Classrooms: 1994-2000. (2001). US Department of Education, Office of Educational Research and Improvement.

${ }^{44}$ Estimates of school demand and tipping behavior disaggregated by grade are available from the authors upon request.

${ }^{45}$ First stage parameter estimates for all 2SLS regressions in this section are presented in table B.2 in the online
} 
and OLS estimates. First, the minority demand coefficient $\hat{\beta}^{M}$ is much larger in the 2SLS regression than in the OLS regression, while the White demand coefficient $\hat{\beta}^{W}$ stays relatively unchanged. We take this as evidence that the sorting of students across schools with respect to confounding amenities is primarily done by minority parents. ${ }^{46}$ Second, under 2 SLS the standard error on $\hat{\beta}^{W}$ increases substantially more than the standard error on $\hat{\beta}^{M}$. We take this as evidence that the pattern of sorting of Whites across schools changed more over the sample period in comparison to the pattern of sorting of minorities. ${ }^{47}$

Our instrumental variable is valid conditional on school-race and year-race fixed effects, hence we can avoid additional assumptions on the exogeneity of other control variables by not including them in our preferred specification. ${ }^{48}$ However, to provide evidence for the robustness of the results in our preferred specification, we also show that our main estimates do not change when we add private amenities (specification 3), peer characteristics (specification 4) and school quality (specification 5) as control variables. This suggests that the racial composition of schools is indeed an important social amenity, and our instrument is valid.

In summary, we find that a strong determinant of parents' enrollment decisions for their children is the racial makeup of their children's prospective peers. ${ }^{49}$ This constitutes evidence that social interactions play a key role in student enrollment decisions. ${ }^{50}$

appendix. First stage parameter estimates for 2SLS regressions in section 5 are available from the authors upon request.

${ }^{46}$ If unobserved confounding private amenities that minorities dislike (like) and to which Whites are indifferent are positively (negatively) serially correlated, then the OLS estimator will underestimate the causal effect of $s_{j t-1}$ on minority demand, but such bias would not exist in the OLS estimator of the causal effect on White demand. Indeed, we find that the minority estimates of the other amenities change from the OLS to the 2SLS regression, while the White estimates do not (see table B.1 in the online appendix).

${ }^{47}$ More precisely, the standard errors on $\hat{\beta}^{W}$ increase substantially more than the standard errors on $\hat{\beta}^{M}$ because the cross-sectional variance of $n_{j t}^{W} / N_{t}^{W}$ increases over time, whereas the cross-sectional variance of $n_{j t}^{M} / N_{t}^{M}$ does not. This implies that the IV uses relatively more variation from minority enrollments than from White enrollments, since $n_{j \tau}^{r} / N_{\tau}^{r}$ is used to create the IVs for a fixed $\tau$ prior to 2002. It follows that more variation within school and over time in the unobservable determinants of White demand $\left(\hat{\epsilon}^{W}\right)$ is unaccounted for in comparison with such variation in the unobservable determinants of minority demand $\left(\hat{\epsilon}^{M}\right)$. As a result, in the 2SLS regression the standard errors clustered by school-race are higher for White demand than for minority demand.

${ }^{48}$ In section 3 we discussed another important reason that specification 2 is our preferred specification. Because identification of tipping behavior due to race requires us to include the indirect effects of $s_{j t-1}$ on parents' demand through other amenities in our estimate of $\beta^{r}$, controlling for post-determined amenities is not appropriate even if these amenities were exogenous, as their inclusion may shut off a particular causal channel of the effect of minority share on race-specific demand.

${ }^{49}$ We find statistically indistinguishable results when demand is specified in first differences instead of with schoolrace fixed effects, which is evidence that the unobservables in our 2SLS regressions are not serially correlated (Wooldridge (2002)).

${ }^{50}$ When we reestimate our preferred specification and include ZIP code-year-race fixed effects, we obtain estimates of $\hat{\beta}^{W}=1.83$ and $\hat{\beta}^{M}=6.62$ with standard errors of 3.19 and 1.41 respectively. We are unable to reject that these parameters are the same as the parameters in our preferred specification. Because these fixed effects absorb all neighborhood-race-year specific determinants of school choice, we interpret this as evidence that parents value the racial composition of their children's school independently of the racial composition of their neighborhood. Moreover, unobserved neighborhood amenities correlated to the racial composition of schools do not bias our parameter estimates. 


\subsection{Estimation of Tipping Points and Stable Equilibria}

In figure 4, we present graphical simulations of the expected minority share in three LA County schools that exhibit qualitatively different tipping behavior. These differences in tipping behavior could arise because of differences in the levels of observed and unobserved amenities in the schools.

The simulation figure for Nancy Cory Elementary is typical of schools in our sample. In addition to an integrated tipping point near $s=0.6$, this school possesses stable, segregated equilibria for very low and very high values of $s$. Vasquez High does not possess a tipping point, as the simulated curve does not cross the 45 degree line from below at any point. However, it possesses a single stable, segregated minority equilibrium. Finally, Gretchen Whitney High also lacks a tipping point, but possesses a single stable, segregated white equilibrium. We describe Nancy Cory Elementary as typical because, as shown in the first column of table 3, we find a tipping point in a majority of schools in our sample in $2006 .{ }^{51}$ We also find stable, segregated White equilibria in approximately $83 \%$ of schools, and stable, segregated minority equilibria in approximately $80 \%$ of schools. These proportions are similar for different years of our sample, as presented in table B.3 in the online appendix.

In figure 5a we show the 2006 histogram of the locations of tipping points for all schools in Los Angeles for which we identified tipping points. The substantial dispersion in the tipping points around the median value of 0.58 underscores one of the contributions of our method since any estimation method that relies on the assumption of common tipping points across schools within year will likely misidentify their locations.

We also show the 2006 histogram of the locations of stable equilibria for all LA County schools in figure 5b. Stable equilibria are doubly counted for schools that possess two of them. Every stable equilibrium that we identify is segregated (i.e., $s^{\star \star} \leq 0.2$ or $s^{\star \star} \geq 0.8$ ). We find substantial heterogeneity in the locations of the segregated, stable equilibria as well as in the existence of a second stable equilibrium (first column of table 3). Although we do find heterogeneity in the locations of tipping points and stable equilibria within schools over time, it is much less pronounced than the heterogeneity in the locations of tipping points and stable equilibria between schools. ${ }^{52}$

We also correlate the existence and locations of tipping points and stable equilibria to observable amenities in order to provide suggestive reduced form evidence of how tipping behavior is associated with differing levels of school amenities. These results for schools in 2006 are presented in table $4 .^{53}$ Schools with larger minority populations tend to tip at higher levels of $s$. Schools with more educated parents and more teachers per capita also tend to tip at higher levels of $s$, and stable

\footnotetext{
${ }^{51}$ We found a similar pattern across other years in our sample, as shown in table B.3 in the online appendix.

${ }^{52}$ The histograms of the locations of tipping points and stable equilibria for other years have a very similar pattern, and can be seen respectively in figures B.2 and B.3 in the online appendix.

${ }^{53}$ The results are very similar for other years in the sample, which is not surprising given the stability of tipping behavior over time.
} 
equilibria in these schools tend to be more White. This is consistent with White parents valuing these amenities relatively more than minority parents. On the other hand, schools with less minority teachers tend to tip at higher levels of $s$, and the stable equilibria in these schools tend to be at lower levels of minority. This is consistent with students having a relative preference for teachers of their same race, as illustrated in figure $2 \mathrm{~b}$. Importantly, we find that ZIP-code fixed effects are statistically significant correlates of tipping behavior. This suggests that private amenities related to the locations of schools determine differences in tipping behavior across schools, and that nearby schools tend to exhibit similar tipping behavior. We stress that the estimates in table 4 should not be interpreted as causal; nevertheless, they are consistent with the theoretical prediction that heterogeneity in private amenities leads to heterogeneity in tipping behavior.

\section{Extensions}

In this section we extend our baseline analysis by relaxing some of our prior assumptions. We focus on three assumptions in particular: the assumption that the log demand is linear in the minority share, the assumption that parents are divided into only two groups and that they group all minorities together when valuing social amenities, and the assumption that the supply of public schooling is perfectly elastic. In section 5.1, we re-estimate the demands for each race semiparametrically in order to allow them to vary flexibly as a function of minority share. In section 5.2, we consider the implications of a more sophisticated model of social interactions in which multiple groups (White, Black and Hispanic parents) have preferences over multiple social amenities (shares of Black and Hispanic enrollment). We estimate schooling demands for multiple groups, adapt our simulation procedure, and discuss the theoretical and computational implications of this increase in dimensionality of the social interaction process. In section 5.3, we describe how our empirical framework can be adapted to a market with a generic supply side, and we offer simulation results under the assumption that supply is perfectly inelastic. We conclude with a comparison of the results from each extension with our baseline results from section 4 . We stress that these extensions are not meant to support a claim that our baseline estimates are robust and accurate, but rather they are meant to illustrate the adaptability of our framework to more complex empirical settings.

\subsection{Flexible Demand Specification}

In the empirical model above, $s_{j}$ enters linearly into parents' demand functions. Although this assumption is not overly restrictive in the sense that it does not imply the existence or location of tipping points or the locations of stable equilibria, it does constrain the shape of $S_{j}$ and rules out the existence of multiple tipping points. More precisely, a linear specification implies that our simulation of $S_{j t}$ will have at most one inflection point and therefore at most one tipping point.

We modify equation (2) to allow for multiple tipping points by specifying demand as 


$$
\log n_{j t}^{r}=f^{r}\left(s_{j t-1}\right)+X_{j t-1}^{\prime} \phi^{r}+\gamma_{j}^{r}+\alpha_{t}^{r}+\epsilon_{j t}^{r}
$$

where $f^{r}$ is some flexible function. The flexible demand equation (7) can be estimated using appropriate non-parametric techniques (Pagan and Ullah (1999), Newey and Powell (2003)) to allow $S_{j t}$ to take on more general shapes. Notably, this approach can potentially identify multiple tipping points (and hence more than two stable equilibria) or one-sided tipping behavior (Card, Mas and Rothstein (2008b)).

We reestimate parental demand functions by flexibly specifying $f^{r}$ as a linear spline of smoothness degree 0 with five knots located at $s=0,0.3,0.7,0.9$, and $1 .{ }^{54}$ Intuitively, $f^{r}$ is estimated off of changes in the endogenous variable $\left(s_{j t-1}\right)$ that are implied by changes in the instrument allowing for these changes in the endogenous variable to have different marginal effects on the outcome variable $\left(\log n_{j t}^{r}\right)$ at different intervals in the domain as defined by the knots. Parameter estimates for the same specifications as in the baseline analysis are presented in table 5. Notably, the results are robust to the inclusion of observed private and social amenities. We cannot reject that White parents are indifferent to minorities in predominantly White schools, although as the minority share of enrollment in a school increases, White parents exhibit an increasingly strong dislike for minority peers. Minority parents have a strong positive preference for minorities in predominantly White schools, and this preference reduces in intensity as the minority share of enrollment in a school increases.

These estimates of parents' preferences for the racial composition of schools are consistent with tipping behavior. Indeed, when we reproduce simulations for the three schools from figure 4 using the flexible demand specification, we find similar evidence of tipping. These results, along with simulations from the baseline specification are presented in figure 6. Histograms of the 2006 locations of tipping points (for all schools in which we found tipping points) are presented in figure 7a. The supports of these histograms are broader than the supports of the histograms of tipping points shown in figure $5 \mathrm{a}$, underscoring widespread heterogeneity in the locations of tipping points. It is immediate that tipping points are clustered at higher levels than before. The evidence suggests that although the baseline specification is not able to fully characterize the tipping behavior of schools in LA County, it does successfully capture heterogeneity in tipping behavior. In particular, allowing for more than one tipping point is not found to be empirically relevant for the analysis of tipping in any school during the sample period. Histograms of the locations of stable equilibria for the flexible specification are presented in figure $7 \mathrm{~b}$. The overwhelming majority of stable equilibria are completely segregated $\left(s^{\star \star}=0\right.$ or $\left.s^{\star \star}=1\right)$. We summarize our simulation results for the flexible specification in the second column of table 3 for 2006. Nearly all schools possess stable White

\footnotetext{
${ }^{54}$ These knots are chosen to reflect the skewed distribution of the minority share, as seen in figure B.1 in the online appendix. The results are qualitatively similar for different choices of knots.
} 
equilibria, and over $85 \%$ of schools possess stable minority equilibria and tipping points. These patterns are similar over time. ${ }^{55}$

\subsection{Multiplicity of Groups and Social Amenities}

Thus far we have assumed that there are only two groups of parents and that there is a single social amenity in parents' demand functions. However, we can enrich our specification by allowing more groups of parents - White, Black and Hispanic parents - to have different preferences over multiple social amenities - the shares of Black and Hispanic students. ${ }^{56}$ We modify demand equation (2) accordingly as:

$$
\log n_{j t}^{r}=\beta_{B}^{r} s_{j t-1}^{B}+\beta_{H}^{r} s_{j t-1}^{H}+X_{j t-1}^{\prime} \phi^{r}+\gamma_{j}^{r}+\alpha_{t}^{r}+\epsilon_{j t}^{r}
$$

for $r \in\{W, B, H\}$.

Specifying multiple social amenities is beneficial in two ways. First, we can implicitly test which social amenity is chiefly responsible for tipping behavior. For example, if the preference parameters for one social amenity are statistically indistinguishable from each other across groups while the preference parameters for another social amenity are precisely estimated to be distinct across groups, then tipping behavior (if it exists) will be due to the latter social amenity. Second, if multiple social amenities are potentially responsible for tipping behavior, then even a linear specification of demand may generate more exotic tipping behavior.

To illuminate this second point, note that in this modified model, tipping is now a higher dimensional phenomenon. There are two implied enrollments that we must simulate, $S_{j t}^{B}$ and $S_{j t}^{H}$, each of which is a function of both $s^{B}$ and $s^{H}$. As a result, $S_{j t}^{B}$ and $S_{j t}^{H}$ are two dimensional surfaces, and tipping points and equilibria in school $j$ are the intersections of these two surfaces with the hyperplane defined by the system of equations

$$
\begin{aligned}
S_{j t}^{B}\left(s^{B}, s^{H}\right) & =s^{B} \\
S_{j t}^{H}\left(s^{B}, s^{H}\right) & =s^{H}
\end{aligned}
$$

in the four dimensional $\left(S^{B}, S^{H}, s^{B}, s^{H}\right)$ space. This hyperplane is the analog to the 45 degree line in the simulations presented above.

We estimate the parental demand system for schooling given in equation (8). Instruments are constructed in a similar fashion as before. Regression results are presented in table 6 for all specifications and are robust to the inclusion of private amenities and social amenities. White parents have a strong distaste for Black peers but no preference for Hispanic peers. This is consistent

\footnotetext{
${ }^{55}$ Figures B.4 and B.5 and Table B.4 in the online appendix present the results for years 2002-2005.

${ }^{56}$ In this section only we group Asian, Pacific Islander, American Indian and Alaskan Native parents with White parents.
} 
with our previous findings that White parents had a moderate distaste for minority peers. Black parents prefer Black peers strongly and Hispanic peers somewhat less so, but Hispanic parents have a strong preference for both Black and Hispanic peers. ${ }^{57}$ This is consistent with the idea that our previous estimates were averages of the preferences of these two minority subgroups.

The heterogeneity in preferences across groups and social amenities manifests itself in different tipping behavior. We present new tipping diagrams for Nancy Cory Elementary School in figure 8. Given that the complexity of the simulation procedure has increased substantially from two dimensions to four dimensions, we represent the functions $S_{j t}^{B}$ and $S_{j t}^{H}$ in two three dimensional diagrams. In figure 8a, we show the tipping surface $S_{j t}^{B}$ as a function of its arguments $s^{B}$ and $s^{H}$. The shaded region represents the plane for which $S_{j t}^{B}\left(s^{B}, s^{H}\right)=s^{B}$. Points where the tipping surface crosses this plane from below represent tipping points in $s^{B}$, and points where the tipping surface crosses this plane from above represent "partially" stable equilibria in $s^{B}$ (since they may not also be stable equilibria in $s^{H}$, hence they are potentially unstable). In figure $8 \mathrm{~b}$, we show the tipping surface $S_{j t}^{H}$ in similar fashion.

In order to present "fully" stable equilibria (as opposed to partially stable equilibria), we combine both of these results in the contour diagram shown in figure 9. The triangular region defined by $s^{B}+s^{H} \leq 1$ is the domain of our simulated tipping surfaces. The thicker curve represents the locus of points $\left(s^{B}, s^{H}\right)$ for which the tipping surface $S_{j t}^{B}$ intersects the 45 degree plane $S_{j t}^{B}\left(s^{B}, s^{H}\right)=s^{B}$, and the thinner curve represents the locus of points for which the tipping surface $S_{j t}^{H}$ intersects the 45 degree plane $S_{j t}^{H}\left(s^{B}, s^{H}\right)=s^{H}$. The small arrows indicate how Black and Hispanic shares evolve in the respective regions. There are three intersections of the lines, two representing fully stable equilibria at $s^{B} \approx 0.03, s^{H} \approx 0.02$ and at $s^{B} \approx 0.15, s^{H} \approx 0.7$, and one representing a tipping point at $s^{B} \approx 0.20, s^{H} \approx 0.25$. $^{58}$

Histograms of the locations of tipping points and stable equilibria for all schools are presented respectively in figures $10 \mathrm{a}$ and $10 \mathrm{~b}$ for year 2006. In comparison with the baseline specification, a large amount of heterogeneity in the locations of tipping points persists, but more distinctly, we find much greater heterogeneity in the locations of stable equilibria. Indeed, some schools appear to possess integrated stable equilibria around $s^{B}+s^{H}=0.4$. We summarize the results of our simulations with multiple groups and amenities in the third column of table 3 for year 2006.

\footnotetext{
${ }^{57}$ Our estimates of White and Black parents' preferences are consistent with survey evidence from Los Angeles that indicates "Black respondents are the least likely to object to residential integration" while "White respondents are the most likely to object to interracial residential contact" (Bobo and Zubrinsky (1996)), but our estimates of Hispanic parents' preferences for Black peers are inconsistent with this evidence. We speculate that this inconsistency arises because our estimate of Hispanic preferences for Black peers encompasses Hispanic preferences for housing prices, which are likely negatively correlated with $s_{j t}^{B}$. Due to the unavailability of school level price data, we are unable to test this hypothesis. Nevertheless, identification of tipping behavior requires only the full reduced-form effect of $s_{j t}^{B}$ on the choices of Hispanic parents. We discuss this point further in section 5.3.

${ }^{58}$ Although it is difficult to discern visually from figure 9 , at the point $s^{B} \approx 0.15, s^{H} \approx 0.7$ the Black (thicker) curve crosses the Hispanic (thinner) curve in a portion of the Hispanic curve that is increasing in $s^{H}$, which implies a fully stable equilibrium.
} 
Roughly one third of LA County schools possess a tipping point, $43 \%$ of schools possess a stable white equilibrium, and nearly all schools possess a stable minority equilibrium. In comparison with the baseline specification, we find tipping and stable White equilibria to be less prevalent, and stable minority equilibria more prevalent. These results are similar over time, as can be seen in the online appendix.

\subsection{Generalizing the Supply Side}

Thus far, we have assumed that the supply of public schooling is perfectly elastic; that is, schools can instantaneously adjust their supply of school seats to accommodate any demand without affecting any other school amenities. In this section, we formulate a more general version of the model outlined in section 3 which includes prices, generalizing our simulation procedure to explicitly take into account endogenous adjustments in the supply of schooling. We then implement the simulation procedure for the case in which schooling is supplied perfectly inelastically.

We begin by modifying the demand equation (2) as

$$
\log n_{j t}^{r}=\beta^{r} s_{j t-1}+\theta^{r} P_{j t-1}+X_{j t-1}^{\prime} \phi^{r}+\gamma_{j}^{r}+\alpha_{t}^{r}+\epsilon_{j t}^{r}
$$

by adding $P_{j t-1}$, the implicit price of school $j$. Define $\Phi_{j t-1}(s)$ as the counterfactual vector of minority shares of all schools when $s_{j}=s$. $\Phi_{j t-1}$ may differ depending on the details of the counterfactual. For example, if the counterfactual level of $s_{j}=s$ is achieved through transfers of whites and minorities into or out of the county as a whole, then $\Phi_{j t-1}(s)=\left(s_{1 t-1}, \ldots, s_{j-1, t-1}, s, s_{j+1, t-1}, \ldots, s_{J t-1}\right)$. Indeed, we use this counterfactual for all simulations in this paper. To maintain full generality in our exposition, we can write $\Phi_{j t-1}=\left(s_{1 t-1}(s), \ldots, s_{j-1, t-1}(s), s, s_{j+1, t-1}(s), \ldots, s_{J t-1}(s)\right)$. For instance, if the counterfactual level of $s$ is achieved through a sorting of students into and out of school $k \neq j$ only, then we would have $s_{k t-1}(s) \neq s_{k t-1}$ and $s_{j^{\prime} t-1}(s)=s_{j^{\prime} t-1} \quad \forall j^{\prime} \neq k, j$.

Given consistent estimates of $\beta^{r}$ and $\theta^{r}$, we generalize the simulation process to identify tipping behavior as follows: ${ }^{59}$ for each school $j$ in year $t$, we pick counterfactual values of $\Phi_{j t-1}$ and recalculate the endogenous vector of prices for all schools, $\tilde{P}_{t-1} \equiv P_{t-1}\left(\Phi_{j t-1}\right)=\left(P_{1 t-1}\left(\Phi_{j t-1}\right), \ldots, P_{J t-1}\left(\Phi_{j t-1}\right)\right)$, that balances demand with supply for each school $j^{\prime}=1, \ldots, J$ according to the equilibrium conditions

\footnotetext{
${ }^{59}$ The assumption of perfectly elastic school supply in our baseline analysis only affects simulation of $S_{j t}$, not the demand estimation. To the extent that $P_{j t-1}$ and $P_{k t-1}, k \neq j$, are both affected by a change in $s_{j t-1}, \beta^{r}$ captures the full reduced-form effect of a change in $s_{j t-1}$ on the race $r$ demand for school $j$. This includes both the direct effect of minority share on demand and any indirect effects due to concomitant changes in the prices of any school. During simulation, when $s \neq s_{j t-1}$, non-linear effects in price are less likely to be fully captured by the parameter estimates at $s_{j t-1}$, and this problem will be exacerbated for counterfactual values of $s$ far from $s_{j t-1}$. Estimating demand more flexibly as done in section 5.1 can mitigate this issue, particularly with a richer data set with greater heterogeneity in $s_{j}$ within schools and over time.
} 


$$
\begin{aligned}
N_{j^{\prime} t}\left(\Phi_{j t-1}, \tilde{P}_{t-1}\right)= & \tilde{n}_{j^{\prime} t}^{W}\left(\Phi_{j t-1}, \tilde{P}_{t-1}\right)+\tilde{n}_{j^{\prime} t}^{M}\left(\Phi_{j t-1}, \tilde{P}_{t-1}\right) \\
\tilde{n}_{j^{\prime} t}^{r}\left(\Phi_{j t-1}, \tilde{P}_{t-1}\right)= & \frac{n_{j^{\prime} t}^{r}\left(\Phi_{j t-1}, \tilde{P}_{t-1}\right)}{\sum_{k} n_{k t}^{r}\left(\Phi_{j t-1}, \tilde{P}_{t-1}\right)} \cdot N_{t}^{r} \\
n_{j^{\prime} t}^{r}\left(\Phi_{j t-1}, \tilde{P}_{t-1}\right)= & \exp \left(\log \left(n_{j^{\prime} t}^{r}\right)+\hat{\beta}^{r}\left(s_{j^{\prime} t-1}(s)-s_{j^{\prime} t-1}\right)\right. \\
& \left.+\hat{\theta}^{r}\left(P_{j^{\prime} t-1}\left(\Phi_{j t-1}\right)-P_{j^{\prime} t-1}\right)\right)
\end{aligned}
$$

where $N_{t}^{r}=\sum_{k} n_{k t}^{r}, s_{j t-1}(s) \equiv s$, and $N_{j^{\prime} t}\left(\Phi_{j t-1}, \tilde{P}_{t-1}\right)$ is the supply of school $j^{\prime}$ at year $t$. Equation (12) equates supply and demand in each school. Equation (13) rescales simulated demand for each school, ensuring that we re-sort only those students who are actually observed in period $t$. Equation (14) captures the fact that simulated enrollments are derived from the estimated demands for schooling, which are generally a function of prices as well. Given such an equilibrium, we can compute $S_{j}\left(\Phi_{j t-1}\right)$ as

$$
S_{j}\left(\Phi_{j t-1}, \tilde{P}_{t-1}\right)=\frac{\tilde{n}_{j t}^{M}\left(\Phi_{j t-1}, \tilde{P}_{t-1}\right)}{\tilde{n}_{j t}^{M}\left(\Phi_{j t-1}, \tilde{P}_{t-1}\right)+\tilde{n}_{j t}^{W}\left(\Phi_{j t-1}, \tilde{P}_{t-1}\right)}
$$

We replicate our analysis under the assumption that supply is inelastic. ${ }^{60}$ Under this assumption, equation (12) can be rewritten as

$$
n_{j^{\prime} t}^{W}+n_{j^{\prime} t}^{M}=\tilde{n}_{j^{\prime} t}^{W}\left(\Phi_{j t-1}, \tilde{P}_{t-1}\right)+\tilde{n}_{j^{\prime} t}^{M}\left(\Phi_{j t-1}, \tilde{P}_{t-1}\right) \forall j^{\prime}
$$

Two main difficulties arise in our implementation. First, the implicit prices of each school are unobserved in the data. This makes estimation of $\theta^{r}$ and the use of $P_{t-1}$ in equation (14) unfeasible. ${ }^{61}$ Second, calculating $\tilde{P}_{t-1}$ may be computationally unfeasible. For each school $j$, year $t$ and counterfactual value $s$, the simulation involves finding a $J$ dimensional vector of prices that balance the demands and supplies of all schools. This simulation is particularly difficult to implement when $J$ is large, as in LA County.

In order to circumvent the first difficulty, we assume that Whites and minorities value money equally, i.e. $\theta^{W}=\theta^{M}=\theta$. This allows us to re-write equation (11) as

\footnotetext{
${ }^{60}$ More information about how supply changes with prices could be incorporated into the left hand side of equation (12). This modification to the simulation procedure would allow for imperfectly elastic supply. In our application, we lack such information, hence we conduct our analysis only for the polar cases of perfectly elastic and perfectly inelastic supply.

${ }^{61}$ Even under the assumption that neighborhood prices can proxy for the implicit price of each school, yearly data at this level of geographical detail are not publicly available.
} 


$$
\log n_{j t}^{r}=\beta^{r} s_{j t-1}+X_{j t-1}^{\prime} \phi^{r}+\gamma_{j}^{r}+\alpha_{t}^{r}+\underbrace{\epsilon_{j t}^{r}+\theta P_{j t-1}}_{\text {error }}
$$

and equation (14) as

$$
\begin{gathered}
n_{j^{\prime} t}^{r}\left(\Phi_{j t-1}, \tilde{K}_{t-1}\right)=\exp \left(\log \left(n_{j^{\prime} t}^{r}\right)+\hat{\beta}^{r}\left(s_{j^{\prime} t-1}(s)-s_{j^{\prime} t-1}\right)\right. \\
+\underbrace{K_{j^{\prime} t-1}\left(\Phi_{j t-1}\right)}_{\hat{\theta}\left(P_{j^{\prime} t-1}\left(\Phi_{j t-1}\right)-P_{j^{\prime} t-1}\right)})
\end{gathered}
$$

Because our instrumental variables are uncorrelated with the error in equation (17), we can obtain consistent estimates of $\beta^{r}$ without observing prices. ${ }^{62}$ For each counterfactual value of $\Phi_{j t-1}$, we must find the vector $\tilde{K}_{t-1} \equiv K_{t-1}\left(\Phi_{j t-1}\right)=\left(K_{1 t-1}\left(\Phi_{j t-1}\right), \ldots, K_{J t-1}\left(\Phi_{j t-1}\right)\right)$ that satisfies the equilibrium conditions. Because we do not need to estimate $\hat{\theta}$ in order to identify the vector $K_{t-1}\left(\Phi_{j t-1}\right)$ under the assumption $\theta^{W}=\theta^{M}=\theta$, we avoid the need to observe prices.

For the second difficulty, we build on Berry, Levinsohn and Pakes (1995) and write a contraction to find the optimal price level that balances the market:

$$
K_{j t-1}^{i+1}=K_{j t-1}^{i}+\log \left(n_{j t}^{W}\left(s, \tilde{K}_{t-1}^{i}\right)+n_{j t}^{M}\left(s, \tilde{K}_{t-1}^{i}\right)\right)-\log \left(n_{j t}^{W}+n_{j t}^{M}\right) \quad \forall j
$$

where $K_{j t-1}^{i}$ is the value of $K_{j t-1}$ in the $i^{t h}$ iteration. The resulting vector $\tilde{K}_{t-1}$ whose $j^{t h}$ element is $K_{j t-1}$ will be the vector that balances all markets. ${ }^{63}$

In figure 11, we reproduce the simulated curves for three schools under the assumptions of perfectly elastic (baseline) and perfectly inelastic supply and note their similarity. In figures 12a and $12 \mathrm{~b}$, we present histograms for 2006 of the locations of tipping points and stable equilibria respectively under the assumptions of perfectly inelastic supply and $\theta^{W}=\theta^{M}$. As in the baseline case tipping points are distributed over a wide support ranging from $15 \%$ to $85 \%$, and all stable equilibria are segregated. We summarize our simulation results under the assumption of inelastic supply in the last column of table 3. In the inelastic case roughly $75 \%$ of the school possess tipping points, with almost $90 \%$ of the schools possessing a White segregated equilibrium, and a similar proportion featuring a minority segregated equilibrium. These results are similar across time, as

${ }^{62}$ If $P_{j t-1}=f\left(s_{j t-1}\right)$, as suggested in footnote 59 , then $\frac{\partial \log n_{j t}^{r}}{\partial s_{j t-1}}=\beta^{r}+f^{\prime}\left(\Phi_{j t-1}\right) \cdot \theta$. Our instrumental variables will then consistently estimate the marginal effect $\frac{\partial \log n_{j t}^{r}}{\partial s_{j t-1}}$. In the ensuing simulation, equation (18) can be modified as $n_{j t}^{r}\left(\Phi_{j t-1}, \tilde{K}_{t-1}^{\prime}\right)=\exp \left(\log \left(n_{j t}^{r}\right)+\frac{\partial \log n_{j t}^{r}}{\partial s_{j t-1}}\left(s-s_{j t-1}\right)+K_{j t-1}^{\prime}\left(\Phi_{j t-1}\right)\right)$, where $K_{j t-1}^{\prime}\left(\Phi_{j t-1}\right)=K_{j t-1}\left(\Phi_{j t-1}\right)-$ $f^{\prime}\left(\Phi_{j t-1}\right) \cdot \theta \cdot\left(s-s_{j t-1}\right)$ with $K_{j t-1}$ implicitly defined in equation (18).

${ }^{63}$ In a more general implementation where prices are observed, $\theta^{r}$ can be estimated for each $r$, and a similar contraction can be used to find the vector $\tilde{P}_{t-1}$ that balances all markets. 
can be see in the online appendix.

These results suggest that the supply elasticity assumption barely affects the tipping behavior of schools. This is likely due to the assumption that $\theta^{W}=\theta^{M}$. As the counterfactual minority share of school $j$ increases and the school experiences an inflow of students (since $\left|\beta^{M}\right|>\left|\beta^{W}\right|$ ), the resulting increase in $P_{j}$ partially offsets the increase in minority demand and exacerbates the decrease in the White demand. If Whites had a lower disutility for price than minorities do $\left(\left|\theta^{W}\right|<\left|\theta^{M}\right|\right)$, then the resulting increase in $P_{j}$ would offset the increase in minority demand more than it would exacerbate the decrease in White demand. ${ }^{64}$ Thus, $S(\cdot)$ would be flatter for all $s$ if $\left|\theta^{W}\right|<\left|\theta^{M}\right|$.

\subsection{Comparison of Specifications}

We compare our results using the specifications in this section with our baseline results by correlating all implied minority shares across all schools between specifications. In particular, we correlate $S_{j 2006}(s)$ with $S_{j 2006}^{\prime}(s)$ at all points $s \in\{0,0.01, \ldots, 1\}$ for all schools $j$ where $S$ corresponds to the baseline specification and $S^{\prime}$ is simulated under an alternative specification. ${ }^{65}$ We present these correlations in the first column of table 7 . The specification with inelastic supply correlates most highly with the baseline specification, while the specifications with two social amenities and flexibly specified demand are correlated less with the baseline specification.

In order to better understand which features of the market for schooling in LA County are most relevant, we also make an out of sample comparison of the simulation results from our baseline specification of school choice presented in section 4 with the simulation results from the various extensions in section 5. We do so by making an out of sample prediction of the minority shares of enrollment in 2007 for each school under each specification and comparing these four predictions with the actual observed minority shares of enrollments in 2007 for each school. ${ }^{66}$ The out of sample prediction error for school $j$ is defined as

$$
\sigma_{j}=S_{j 2007}\left(s_{j 2006}\right)-s_{j 2007}
$$

The results of this comparison are summarized in the second column of table 7 . The specification with inelastic supply performs slightly better than the baseline specification or the specification with two social amenities. On the other hand, the specification with nonlinear demand for minority

\footnotetext{
${ }^{64}$ If $\theta^{W}=\theta^{M}$, then the inelastic case is similar to a modified perfectly elastic case in which parents have preference parameters $\tilde{\beta}^{r}$ that satisfy $\left|\tilde{\beta}^{M}\right|=\left|\tilde{\beta}^{W}\right|$ and $\tilde{\beta}^{M}-\tilde{\beta}^{W}=\beta^{M}-\beta^{W}$, where $\beta^{r}$ are the preference parameters from the unmodified perfectly elastic case. On the other hand, if $\left|\theta^{W}\right|<\left|\theta^{M}\right|$, then the inelastic case is similar to a modified perfectly elastic case with preference parameters $\tilde{\beta}^{r}$, with $\left|\tilde{\beta}^{M}\right|=\left|\tilde{\beta}^{W}\right|$ and $\tilde{\beta}^{M}-\tilde{\beta}^{W}<\beta^{M}-\beta^{W}$.

${ }^{65}$ In comparing the curve rather than just the specific points of equilibrium in the curve, we are providing a more general comparison of the tipping behavior under alternative assumptions of the model. If we instead compared only the locations of tipping points and stable equilibria across specifications, we would have to restrict our sample for comparison to those schools for which we identify tipping points (or the same number of stable equilibria) under both specifications.

${ }^{66}$ We make this comparison for 1690 of the 1692 schools in our sample since two schools ceased operations in 2007.
} 
peers performs markedly worse, which may indicate that the nonlinear demand estimates over-fit the data within the sample. Overall, the out of sample comparison of specifications is consistent with the in sample correlations of specifications described above. ${ }^{67}$

\section{Conclusion}

The Schelling model of segregation explains seemingly complex dynamics in a simple framework. In this paper, we provide an empirical implementation of this model that offers several advantages over previous approaches. In particular, we argue that quasi-experimental approaches to identify tipping behavior rely on strong assumptions that appear to be empirically invalid. Instead, we offer a structural method to identify tipping points and stable equilibria that allows for heterogeneity in tipping behavior and can be adapted to analyze tipping behavior in more complex settings.

We implement our methodology in the case of segregation in public schools and find that the market for public schooling in Los Angeles County is both diverse and dynamic. We use instrumental variables to identify the causal effects of a change in the previous year's minority share of a school on the demand for subsequent schooling by parents of different races for each public school in LA County from 2002-2006. With these estimates, we are able to identify school specific tipping points and stable equilibria via simulation. In doing so, we document substantial heterogeneity in the tipping behavior across schools and limited heterogeneity in the tipping behavior within schools over time. The statistical comparison of our results under various specifications of the social interactions present in the market for public schooling leads us to speculate that the predominant racial margin of social interaction falls between White and minority peers, and the margin of social interaction between Black and Hispanic peers, while prevalent, explains less of the evolution in minority enrollments in LA County schools. This exercise illustrates by example that our estimation procedure is adaptable to various empirical and theoretical frameworks.

Our framework highlights the need for a more conservative view of the state of the art in the subject of tipping behavior and segregation, as better data is needed to undertake a more complete analysis on the topic. With improved data, it would be useful to explore further substitution effects between schools along the lines of Berry, Levinsohn and Pakes (1995) and Bayer and McMillan (2010) and to allow for the presence of moving costs in the spirit of Bayer et al. (2011). In addition,

\footnotetext{
${ }^{67}$ We also present histograms of $\sigma_{j}$ for each specification in figure B.10 in the online appendix. The baseline, nonlinear demand and inelastic supply specifications all tend to under-predict 2007 minority enrollments. This is likely due to the fact that there is a modest net influx of minority students into LA County in 2007 relative to our sample period. When we allow parents to have heterogeneous preferences over two social amenities, this underprediction is mitigated by the more complex responsiveness of parents to the racial composition of schools (in fact, minority enrollment is slightly over-predicted).
} 
the availability of price data would allow us to explore the complex interactions that have been documented between social amenities and prices (Kiel and Zabel (1996)). We believe that the approach developed here serves as a platform upon which these features can be added.

\section{References}

Banerjee, A.V. 1992. "A Simple Model of Herd Behavior." The Quarterly Journal of Economics 107(3):797-817.

Banzhaf, H. Spencer and Randall P. Walsh. 2013. "Segregation and Tiebout sorting: The link between place-based investments and neighborhood tipping." Journal of Urban Economics 74(0):83 $-98$.

Bayer, P. and C. Timmins. 2005. "On the equilibrium properties of locational sorting models." Journal of Urban Economics 57(3):462-477.

Bayer, P. and C. Timmins. 2007. "Estimating Equilibrium Models Of Sorting Across Locations." The Economic Journal 117(518):353-374.

Bayer, P., F. Ferreira and R. McMillan. 2007. "A Unified Framework for Measuring Preferences for Schools and Neighborhoods." Journal of Political Economy 115(4):588-638.

Bayer, P., R. McMillan, A. Murphy and C. Timmins. 2011. A dynamic model of demand for houses and neighborhoods. Technical report National Bureau of Economic Research.

Bayer, P., R. McMillan and K. Rueben. 2004. An equilibrium model of sorting in an urban housing market. Technical report National Bureau of Economic Research.

Bayer, Patrick J. and Robert McMillan. 2010. "Choice and Competition in Education Markets." Economic Research Initiatives at Duke (ERID) Working Paper 48:1-45.

Becker, G.S. and K.M. Murphy. 2000. Social Economics: Market Behavior in a Social Environment. Harvard University Press.

Berry, S., J. Levinsohn and A. Pakes. 1995. "Automobile Prices in Market Equilibrium." Econometrica 63(4):841-890.

Berry, S.T. 1994. "Estimating Discrete-Choice Models of Product Differentiation." The RAND Journal of Economics pp. 242-262.

Billings, Stephen B., David J. Deming and Jonah E. Rockoff. 2012. School Segregation, Educational Attainment and Crime: Evidence from the end of busing in Charlotte-Mecklenburg. Working Paper 18487 National Bureau of Economic Research.

Black, S. and S. Machin. 2011. "Housing valuations of school performance." Handbook of the Economics of Education 3:485-519.

Black, S.E. 1999. "Do better schools matter? Parental valuation of elementary education." The Quarterly Journal of Economics 114(2):577-599. 
Blume, Lawrence and Steven Durlauf. 2003. "Equilibrium concepts for social interaction models." International Game Theory Review 5(03):193-209.

Bobo, Lawrence and Camille L Zubrinsky. 1996. "Attitudes on residential integration: Perceived status differences, mere in-group preference, or racial prejudice?" Social Forces 74(3):883-909.

Bobo, L.D., C.Z. Charles, M. Krysan, A.D. Simmons and G.M. Fredrickson. 2012. "The Real Record on Racial Attitudes." Social Trends in American Life: Findings from the General Social Survey since 1972 p. 38.

Boustan, L.P. 2012. "School Desegregation and Urban Change: Evidence from City Boundaries." American Economic Journal: Applied Economics 4(1):85-108.

Brock, William A and Steven N Durlauf. 2001a. "Discrete choice with social interactions." The Review of Economic Studies 68(2):235-260.

Brock, William A and Steven N Durlauf. 2001b. "Interactions-based models." Handbook of econometrics 5:3297-3380.

Bruch, E.E. and R.D. Mare. 2006. "Neighborhood Choice and Neighborhood Change." American Journal of Sociology 112(3):667-708.

Caetano, Gregorio. 2012. "Neighborhood Sorting and the Valuation of Public School Quality." Mimeo .

Card, D. 2001. "Immigrant Inflows, Native Outflows, and the Local Labor Market Impacts of Higher Immigration." Journal of Labor Economics 19(1):22-64.

Card, D. 2009. "Immigration and Inequality." NBER Working Paper.

Card, D., A. Mas and J. Rothstein. 2008a. "Tipping and the Dynamics of Segregation." Quarterly Journal of Economics 123(1):177-218.

Card, D., A. Mas and J. Rothstein. 2008b. "Are Mixed Neighborhoods Always Unstable? Two-Sided and One-Sided Tipping." NBER Working Paper .

Easterly, William. 2009. "Empirics of strategic interdependence: the case of the racial tipping point." The BE Journal of Macroeconomics 9(1).

Echenique, F., R.G. Fryer Jr and A. Kaufman. 2006. "Is school segregation good or bad?" The American economic review pp. 265-269.

Frankel, D.M. and O. Volij. 2011. "Measuring school segregation." Journal of Economic Theory 146(1):1-38.

Ioannides, Y.M. and J.E. Zabel. 2008. "Interactions, neighborhood selection and housing demand." Journal of Urban Economics 63(1):229-252.

Jackson, Clement Kirabo. 2009. "Student demographics, teacher sorting, and teacher quality: Evidence from the end of school desegregation." The Journal of Labor Economics 27(2):213-256.

Jackson, M.O. and L. Yariv. 2006. "Diffusion on Social Networks." Économie Publique/Public Economics 16(16). 
Kandori, Michihiro, George J Mailath and Rafael Rob. 1993. "Learning, mutation, and long run equilibria in games." Econometrica: Journal of the Econometric Society pp. 29-56.

Kiel, Katherine A and Jeffrey E Zabel. 1996. "House price differentials in US cities: Household and neighborhood racial effects." Journal of housing economics 5(2):143-165.

Levinthal, Daniel A and James G March. 1993. "The myopia of learning." Strategic management journal 14(S2):95-112.

Marques, D. and FMS Lima. 2010. "Some Transcendental Functions that Yield Transcendental Values for Every Algebraic Entry." Arxiv preprint arXiv:1004.1668 .

Maskell, Peter and Anders Malmberg. 2007. "Myopia, knowledge development and cluster evolution." Journal of Economic Geography 7(5):603-618.

McFadden, Daniel. 1973. Conditional Logit Analysis of Qualitative Choice Behavior. Frontiers in Econometrics New York: Academic Press.

Newey, Whitney K and James L Powell. 2003. "Instrumental variable estimation of nonparametric models." Econometrica 71(5):1565-1578.

Ostrom, E. 2000. "Collective action and the evolution of social norms." The Journal of Economic Perspectives pp. 137-158.

Pagan, A. and A. Ullah. 1999. Nonparametric Econometrics. Cambridge Univ Pr.

Pan, Jessica Y. 2011. "Gender Segregation in Occupations: The Role of Tipping and Social Interactions." Working Paper .

Pancs, Romans and Nicolaas J Vriend. 2007. "Schelling's spatial proximity model of segregation revisited." Journal of Public Economics 91(1):1-24.

Pryor, Frederic L. 1971. "An Empirical Note on the Tipping Point." Land Economics 47(4):413-417.

Schelling, Thomas C. 1969. "Models of Segregation." The American Economic Review 59(2):488493.

Schelling, Thomas C. 1971. "Dynamic Models of Segregation." Journal of Mathematical Sociology 1:143-186.

Schelling, Thomas C. 2006. Micromotives and Macrobehavior. WW Norton \& Company.

Vartanian, T.P. and P.M. Gleason. 1999. "Do neighborhood conditions affect high school dropout and college graduation rates?" Journal of Socio-Economics 28(1):21-41.

Wooldridge, Jeffrey M. 2002. Econometric Analysis Cross Section Panel. MIT press.

Zhang, J. 2009. "Tipping and Residential Segregation: A Unified Schelling Model." Journal of Regional Science 51:167-193. 
Table 1: Summary Statistics

\begin{tabular}{|c|c|c|c|c|c|}
\hline Variable & 2002 & 2003 & 2004 & 2005 & 2006 \\
\hline Minority Share & $\begin{array}{c}0.79 \\
(0.24)\end{array}$ & $\begin{array}{c}0.80 \\
(0.23)\end{array}$ & $\begin{array}{c}0.80 \\
(0.24)\end{array}$ & $\begin{array}{c}0.81 \\
(0.23)\end{array}$ & $\begin{array}{c}0.81 \\
(0.23)\end{array}$ \\
\hline $\begin{array}{l}\text { Academic Performance Index } \\
(\text { API })\end{array}$ & $\begin{array}{c}658 \\
(113)\end{array}$ & $\begin{array}{c}691 \\
(111)\end{array}$ & $\begin{array}{c}692 \\
(114)\end{array}$ & $\begin{array}{c}700 \\
(112)\end{array}$ & $\begin{array}{c}715 \\
(111)\end{array}$ \\
\hline $\begin{array}{l}\text { Share of Students Eligible for a } \\
\text { Free or Reduced Price Lunch }\end{array}$ & $\begin{array}{c}0.62 \\
(0.48)\end{array}$ & $\begin{array}{c}0.63 \\
(0.30)\end{array}$ & $\begin{array}{c}0.63 \\
(0.47)\end{array}$ & $\begin{array}{c}0.62 \\
(0.31)\end{array}$ & $\begin{array}{c}0.61 \\
(0.30)\end{array}$ \\
\hline $\begin{array}{l}\text { Share of Students with a Parent } \\
\text { with Some College Education }\end{array}$ & $\begin{array}{c}0.48 \\
(0.24)\end{array}$ & $\begin{array}{c}0.48 \\
(0.24)\end{array}$ & $\begin{array}{c}0.47 \\
(0.25)\end{array}$ & $\begin{array}{c}0.46 \\
(0.26)\end{array}$ & $\begin{array}{c}0.46 \\
(0.26)\end{array}$ \\
\hline $\begin{array}{l}\text { Full Time Equivalent Teachers } \\
\text { per Student }\end{array}$ & $\begin{array}{c}0.06 \\
(0.02)\end{array}$ & $\begin{array}{c}0.06 \\
(0.02)\end{array}$ & $\begin{array}{c}0.06 \\
(0.02)\end{array}$ & $\begin{array}{c}0.06 \\
(0.02)\end{array}$ & $\begin{array}{c}0.06 \\
(0.03)\end{array}$ \\
\hline $\begin{array}{l}\text { Share of Teachers with a } \\
\text { Bachelor's Degree }\end{array}$ & $\begin{array}{c}0.82 \\
(0.12)\end{array}$ & $\begin{array}{c}0.80 \\
(0.12)\end{array}$ & $\begin{array}{c}0.81 \\
(0.12)\end{array}$ & $\begin{array}{c}0.81 \\
(0.12)\end{array}$ & $\begin{array}{c}0.80 \\
(0.12)\end{array}$ \\
\hline $\begin{array}{l}\text { Share of Teachers with a } \\
\text { Master's Degree }\end{array}$ & $\begin{array}{c}0.35 \\
(0.15)\end{array}$ & $\begin{array}{c}0.35 \\
(0.15)\end{array}$ & $\begin{array}{c}0.38 \\
(0.15)\end{array}$ & $\begin{array}{c}0.39 \\
(0.14)\end{array}$ & $\begin{array}{c}0.42 \\
(0.15)\end{array}$ \\
\hline $\begin{array}{l}\text { Share of Teachers who are } \\
\text { Minorities }\end{array}$ & $\begin{array}{c}0.39 \\
(0.24)\end{array}$ & $\begin{array}{c}0.38 \\
(0.23)\end{array}$ & $\begin{array}{c}0.40 \\
(0.23)\end{array}$ & $\begin{array}{c}0.41 \\
(0.23)\end{array}$ & $\begin{array}{c}0.42 \\
(0.24)\end{array}$ \\
\hline Computers per Student & $\begin{array}{c}0.19 \\
(0.14)\end{array}$ & $\begin{array}{c}0.21 \\
(0.14)\end{array}$ & $\begin{array}{c}0.23 \\
(0.14)\end{array}$ & $\begin{array}{c}0.25 \\
(0.16)\end{array}$ & $\begin{array}{c}0.28 \\
(0.28)\end{array}$ \\
\hline $\begin{array}{l}\text { Internet Connected Computers } \\
\text { per Student }\end{array}$ & $\begin{array}{c}0.04 \\
(0.04)\end{array}$ & $\begin{array}{c}0.05 \\
(0.04)\end{array}$ & $\begin{array}{c}0.05 \\
(0.05)\end{array}$ & $\begin{array}{c}0.06 \\
(0.04)\end{array}$ & $\begin{array}{c}0.06 \\
(0.04)\end{array}$ \\
\hline $\begin{array}{l}\text { Number of Staff Providing } \\
\text { English Learning Services to } \\
\text { Spanish Speakers per Student }\end{array}$ & $\begin{array}{c}0.01 \\
(0.02)\end{array}$ & $\begin{array}{c}0.01 \\
(0.01)\end{array}$ & $\begin{array}{c}0.01 \\
(0.02)\end{array}$ & $\begin{array}{c}0.01 \\
(0.01)\end{array}$ & $\begin{array}{c}0.01 \\
(0.01)\end{array}$ \\
\hline $\begin{array}{l}\text { Calendar Dummy (equal to } 1 \text { if } \\
\text { school operates on a traditional } \\
9 \text { month calendar, } 0 \text { otherwise) }\end{array}$ & $\begin{array}{c}0.73 \\
(0.44)\end{array}$ & $\begin{array}{c}0.74 \\
(0.44)\end{array}$ & $\begin{array}{c}0.76 \\
(0.43)\end{array}$ & $\begin{array}{c}0.77 \\
(0.42)\end{array}$ & $\begin{array}{c}0.79 \\
(0.41)\end{array}$ \\
\hline Number of Schools & & & 1692 & & \\
\hline
\end{tabular}

Note: We present means of variables with standard deviations in parentheses. See text for description of variables and their data sources. 
Table 2: Parameter Estimates for Schooling Demand by Race, 2002-2006

\begin{tabular}{lccccc}
\hline Variable & $(1)$ & $(2)$ & $(3)$ & $(4)$ & $(5)$ \\
\hline Minority Share, White & $-1.72^{* *}$ & -1.55 & -1.91 & -2.00 & -2.44 \\
Demand $\left(\hat{\beta}^{W}\right)$ & $(0.18)$ & $(1.36)$ & $(1.39)$ & $(1.36)$ & $(1.42)$ \\
Minority Share, & $0.93^{* *}$ & $5.96^{* *}$ & $5.73^{* *}$ & $5.70^{* *}$ & $5.70^{* *}$ \\
Minority Demand $\left(\hat{\beta}^{M}\right)$ & $(0.21)$ & $(0.56)$ & $(0.55)$ & $(0.56)$ & $(0.58)$ \\
Other Private Amenities & No & No & Yes & Yes & Yes \\
Included? & No & No & No & Yes & Yes \\
Other Peer & & & & & \\
Characteristics & No & No & No & No & Yes \\
Included? & Yes & Yes & Yes & Yes & Yes \\
School Quality Included? & & & & & \\
School-Race Fixed & Yes & Yes & Yes & Yes & Yes \\
Effects? & OLS & 2 SLS & 2 SLS & 2 SLS & 2 SLS \\
Year-Race Fixed Effects? & 0.98 & 0.98 & 0.98 & 0.98 & 0.98 \\
\hline Estimation & 16920 & 16920 & 16920 & 16920 & 16920 \\
$R^{2}$ &
\end{tabular}

Notes: The dependent variable is $\log$ enrollment by race, school and year $\left(\log n_{j t}^{r}\right)$. Robust standard errors clustered by school and race are provided in parentheses. Coefficient estimates on other amenities are presented in table B.1 in the online appendix. First stage coefficient estimates for 2SLS specifications are presented in table B.2 in the online appendix.

* - Statistically significant at the $95 \%$ level, ** - Statistically significant at the $99 \%$ level.

Table 3: Prevalence of Tipping Points and Stable Equilibria Across Specifications, 2006

\begin{tabular}{lcccc}
\hline & Baseline & Flexible & Two Social Amenities & Inelastic \\
\hline \hline $\begin{array}{l}\text { Share of Schools With Tipping } \\
\text { Points }\end{array}$ & 0.61 & 0.84 & 0.34 & 0.74 \\
$\begin{array}{l}\text { Share of Schools with a Stable } \\
\text { White Equilibrium }\left(s^{\star \star}<.5\right)\end{array}$ & 0.83 & 0.99 & 0.44 & 0.83 \\
$\begin{array}{l}\text { Share of Schools with a Stable } \\
\text { Minority Equilibrium }\left(s^{\star \star} \geq .5\right)\end{array}$ & 0.78 & 0.85 & 0.94 & 0.86 \\
\hline
\end{tabular}


Table 4: Correlates of Tipping Points and Stable Equilibria, 2006

\begin{tabular}{|c|c|c|c|c|}
\hline Variable & $\begin{array}{l}\text { Existence of } \\
\text { Tipping } \\
\text { Point }\end{array}$ & $\begin{array}{l}\text { Location of } \\
\text { Tipping } \\
\text { Point }\end{array}$ & $\begin{array}{l}\text { Location of } \\
\text { Stable } \\
\text { White Eq. }\end{array}$ & $\begin{array}{l}\text { Location of } \\
\text { Stable Min. } \\
\text { Eq. }\end{array}$ \\
\hline Black Share of Enrollment & $\begin{array}{l}-0.07 \\
(0.18)\end{array}$ & $\begin{array}{l}0.56^{* *} \\
(0.08)\end{array}$ & $\begin{array}{c}-0.065^{* *} \\
(0.009)\end{array}$ & $\begin{array}{c}-0.065^{* *} \\
(0.012)\end{array}$ \\
\hline Hispanic Share of Enrollment & $\begin{array}{l}-0.02 \\
(0.15)\end{array}$ & $\begin{array}{l}0.32^{* *} \\
(0.06)\end{array}$ & $\begin{array}{c}-0.026^{* *} \\
(0.007)\end{array}$ & $\begin{array}{c}-0.057^{* *} \\
(0.010)\end{array}$ \\
\hline $\begin{array}{l}\text { Academic Performance Index } \\
\text { (API) }\end{array}$ & $\begin{array}{l}-0.01 \\
(0.02)\end{array}$ & $\begin{array}{c}0.01 \\
(0.01)\end{array}$ & $\begin{array}{c}-0.002^{* *} \\
(0.001)\end{array}$ & $\begin{array}{l}0.0003 \\
(0.001)\end{array}$ \\
\hline $\begin{array}{l}\text { Share of Students Eligible for } \\
\text { a Free or Reduced Price } \\
\text { Lunch }\end{array}$ & $\begin{array}{l}-0.08 \\
(0.11)\end{array}$ & $\begin{array}{l}-0.07 \\
(0.04)\end{array}$ & $\begin{array}{c}0.008 \\
(0.005)\end{array}$ & $\begin{array}{l}0.014^{*} \\
(0.007)\end{array}$ \\
\hline $\begin{array}{l}\text { Share of Students with a } \\
\text { Parent with Some College } \\
\text { Education }\end{array}$ & $\begin{array}{l}-0.20 \\
(0.11)\end{array}$ & $\begin{array}{l}0.18^{* *} \\
(0.05)\end{array}$ & $\begin{array}{c}-0.016^{* *} \\
(0.005)\end{array}$ & $\begin{array}{c}-0.030^{* *} \\
(0.008)\end{array}$ \\
\hline $\begin{array}{l}\text { Full Time Equivalent } \\
\text { Teachers per Student }\end{array}$ & $\begin{array}{l}-0.96^{*} \\
(0.45)\end{array}$ & $\begin{array}{l}0.87^{*} \\
(0.42)\end{array}$ & $\begin{array}{c}-0.059^{* *} \\
(0.022)\end{array}$ & $\begin{array}{l}-0.125 \\
(0.066)\end{array}$ \\
\hline $\begin{array}{l}\text { Share of Teachers with a } \\
\text { Bachelor's Degree }\end{array}$ & $\begin{array}{c}0.20 \\
(0.14)\end{array}$ & $\begin{array}{l}-0.01 \\
(0.05)\end{array}$ & $\begin{array}{c}0.001 \\
(0.006)\end{array}$ & $\begin{array}{l}-0.003 \\
(0.009)\end{array}$ \\
\hline $\begin{array}{l}\text { Share of Teachers with a } \\
\text { Master's Degree }\end{array}$ & $\begin{array}{c}0.14 \\
(0.11)\end{array}$ & $\begin{array}{c}0.02 \\
(0.04)\end{array}$ & $\begin{array}{l}-0.004 \\
(0.005)\end{array}$ & $\begin{array}{l}-0.013 \\
(0.007)\end{array}$ \\
\hline $\begin{array}{l}\text { Share of Teachers who are } \\
\text { Minorities }\end{array}$ & $\begin{array}{l}-0.07 \\
(0.10)\end{array}$ & $\begin{array}{c}-0.11^{* *} \\
(0.04)\end{array}$ & $\begin{array}{c}0.014^{* *} \\
(0.004)\end{array}$ & $\begin{array}{c}0.021^{* *} \\
(0.006)\end{array}$ \\
\hline Computers per Student & $\begin{array}{c}0.07 \\
(0.04)\end{array}$ & $\begin{array}{l}-0.00 \\
(0.02)\end{array}$ & $\begin{array}{l}-0.001 \\
(0.002)\end{array}$ & $\begin{array}{c}0.003 \\
(0.003)\end{array}$ \\
\hline $\begin{array}{l}\text { Internet Connected } \\
\text { Computers per Student }\end{array}$ & $\begin{array}{l}-0.27 \\
(0.31)\end{array}$ & $\begin{array}{l}-0.07 \\
(0.15)\end{array}$ & $\begin{array}{c}0.006 \\
(0.013)\end{array}$ & $\begin{array}{l}-0.009 \\
(0.023)\end{array}$ \\
\hline $\begin{array}{l}\text { Number of Staff Providing } \\
\text { English Learning Services to } \\
\text { Spanish Speakers per Student }\end{array}$ & $\begin{array}{c}0.18 \\
(0.94)\end{array}$ & $\begin{array}{c}-0.81^{*} \\
(0.40)\end{array}$ & $\begin{array}{l}0.082^{*} \\
(0.041)\end{array}$ & $\begin{array}{c}0.074 \\
(0.064)\end{array}$ \\
\hline $\begin{array}{l}=1 \text { if school operates on a } \\
\text { traditional } 9 \text { month calendar }\end{array}$ & $\begin{array}{l}-0.03 \\
(0.03)\end{array}$ & $\begin{array}{l}0.06^{* *} \\
(0.01)\end{array}$ & $\begin{array}{c}-0.008^{* *} \\
(0.002)\end{array}$ & $\begin{array}{c}-0.008^{* *} \\
(0.002)\end{array}$ \\
\hline $\begin{array}{l}\text { Joint F-stat of significance of } \\
\text { ZIP Code dummies ( } p \text {-value) }\end{array}$ & $\begin{array}{c}3.34 \\
(0.00)\end{array}$ & $\begin{array}{c}3.33 \\
(0.00)\end{array}$ & $\begin{array}{c}3.56 \\
(0.00)\end{array}$ & $\begin{array}{c}4.95 \\
(0.00)\end{array}$ \\
\hline$R^{2}$ & 0.35 & 0.47 & 0.43 & 0.58 \\
\hline Number of Observations & 1692 & 1024 & 1397 & 1319 \\
\hline
\end{tabular}


Table 5: Parameter Estimates for Schooling Demand, 2002-2006: Flexible Demand Specification

\begin{tabular}{|c|c|c|c|c|c|c|}
\hline Variable & & (1) & (2) & (3) & (4) & (5) \\
\hline \multirow[t]{4}{*}{$\begin{array}{l}\text { Minority Share, White } \\
\text { Demand }\left(\hat{\beta}^{W}\right)\end{array}$} & $s \in[0,0.3)$ & $\begin{array}{l}-0.52 \\
(0.27)\end{array}$ & $\begin{array}{c}8.69 \\
(8.16)\end{array}$ & $\begin{array}{c}7.89 \\
(8.04)\end{array}$ & $\begin{array}{c}6.84 \\
(8.14)\end{array}$ & $\begin{array}{c}6.19 \\
(8.28)\end{array}$ \\
\hline & $s \in[0.3,0.7)$ & $\begin{array}{r}-1.26^{* *} \\
(0.17)\end{array}$ & $\begin{array}{l}-5.12^{*} \\
(2.48)\end{array}$ & $\begin{array}{l}-5.44^{*} \\
(2.48)\end{array}$ & $\begin{array}{l}-5.19^{*} \\
(2.40)\end{array}$ & $\begin{array}{l}-5.58^{*} \\
(2.43)\end{array}$ \\
\hline & $s \in[0.7,0.9)$ & $\begin{array}{c}-2.17^{* *} \\
(0.40)\end{array}$ & $\begin{array}{l}-3.64^{*} \\
(1.58)\end{array}$ & $\begin{array}{l}-3.93^{*} \\
(1.63)\end{array}$ & $\begin{array}{l}-4.06^{*} \\
(1.61)\end{array}$ & $\begin{array}{c}-4.36^{* *} \\
(1.67)\end{array}$ \\
\hline & $s \in[0.9,1.0]$ & $\begin{array}{c}-6.03^{* *} \\
(1.26)\end{array}$ & $\begin{array}{c}-30.80^{* *} \\
(6.31)\end{array}$ & $\begin{array}{c}-31.05^{* *} \\
(6.35)\end{array}$ & $\begin{array}{c}-31.49^{* *} \\
(6.45)\end{array}$ & $\begin{array}{c}-31.88^{* *} \\
(6.45)\end{array}$ \\
\hline \multirow[t]{4}{*}{$\begin{array}{l}\text { Minority Share, Minority } \\
\text { Demand }\left(\hat{\beta}^{M}\right)\end{array}$} & $s \in[0,0.3)$ & $\begin{array}{c}0.85 \\
(1.08)\end{array}$ & $\begin{array}{l}18.97^{*} \\
(8.95)\end{array}$ & $\begin{array}{l}17.74^{*} \\
(8.96)\end{array}$ & $\begin{array}{c}18.57^{*} \\
(9.03)\end{array}$ & $\begin{array}{l}18.76^{*} \\
(9.09)\end{array}$ \\
\hline & $s \in[0.3,0.7)$ & $\begin{array}{c}1.06^{* *} \\
(0.22)\end{array}$ & $\begin{array}{l}6.68^{* *} \\
(1.14)\end{array}$ & $\begin{array}{l}6.34^{* *} \\
(1.12)\end{array}$ & $\begin{array}{l}6.09^{* *} \\
(1.11)\end{array}$ & $\begin{array}{l}6.20^{* *} \\
(1.10)\end{array}$ \\
\hline & $s \in[0.7,0.9)$ & $\begin{array}{r}0.97^{* *} \\
(0.18)\end{array}$ & $\begin{array}{l}5.62^{* *} \\
(0.67)\end{array}$ & $\begin{array}{l}5.52^{* *} \\
(0.68)\end{array}$ & $\begin{array}{l}5.54^{* *} \\
(0.67)\end{array}$ & $\begin{array}{l}5.63^{* *} \\
(0.68)\end{array}$ \\
\hline & $s \in[0.9,1.0]$ & $\begin{array}{l}-0.04 \\
(0.45)\end{array}$ & $\begin{array}{l}7.29^{* *} \\
(2.17)\end{array}$ & $\begin{array}{l}6.84^{* *} \\
(2.07)\end{array}$ & $\begin{array}{l}7.11^{* *} \\
(2.10)\end{array}$ & $\begin{array}{l}7.23^{* *} \\
(2.11)\end{array}$ \\
\hline $\begin{array}{l}\text { Other Private Amenities } \\
\text { Included? }\end{array}$ & & No & No & Yes & Yes & Yes \\
\hline $\begin{array}{l}\text { Other Peer Characteristics } \\
\text { Included? }\end{array}$ & & No & No & No & Yes & Yes \\
\hline School Quality Included? & & No & No & No & No & Yes \\
\hline $\begin{array}{l}\text { School-Race Fixed } \\
\text { Effects? }\end{array}$ & & Yes & Yes & Yes & Yes & Yes \\
\hline Year-Race Fixed Effects? & & Yes & Yes & Yes & Yes & Yes \\
\hline Estimation & & OLS & 2SLS & 2SLS & 2SLS & 2SLS \\
\hline$R^{2}$ & & 0.98 & 0.98 & 0.98 & 0.98 & 0.98 \\
\hline Number of Observations & & 16920 & 16920 & 16920 & 16920 & 16920 \\
\hline
\end{tabular}

Notes: The dependent variable is $\log$ enrollment by race, school and year $\left(\log n_{j t}^{r}\right)$. Minority share is specified using a spline of smoothness 0 with five knots and is instrumented by the IV described in section 3 . The coefficient estimates for private amenities and peer characteristics are available on request. Robust standard errors clustered by school and race are provided in parentheses.

* - Statistically significant at the $95 \%$ level, ${ }^{* *}$ - Statistically significant at the $99 \%$ level. 
Table 6: Parameter Estimates for Schooling Demand, 2002-2006: Two Social Amenities

\begin{tabular}{|c|c|c|c|c|c|}
\hline Variable & $(1)$ & $(2)$ & $(3)$ & $(4)$ & $(5)$ \\
\hline $\begin{array}{l}\text { Black Share, White } \\
\text { Demand }\left(\hat{\beta}_{B}^{W}\right)\end{array}$ & $\begin{array}{c}-1.21^{* *} \\
(0.39)\end{array}$ & $\begin{array}{c}-4.28^{* *} \\
(1.89)\end{array}$ & $\begin{array}{l}-4.74^{*} \\
(1.96)\end{array}$ & $\begin{array}{c}-5.06^{* *} \\
(1.92)\end{array}$ & $\begin{array}{c}-5.64^{* *} \\
(2.01)\end{array}$ \\
\hline $\begin{array}{l}\text { Hispanic Share, White } \\
\text { Demand }\left(\hat{\beta}_{H}^{W}\right)\end{array}$ & $\begin{array}{c}-1.34^{* *} \\
(0.28)\end{array}$ & $\begin{array}{c}0.32 \\
(1.48)\end{array}$ & $\begin{array}{c}0.00 \\
(1.53)\end{array}$ & $\begin{array}{l}-0.20 \\
(1.49)\end{array}$ & $\begin{array}{l}-0.93 \\
(1.54)\end{array}$ \\
\hline $\begin{array}{l}\text { Black Share, Black } \\
\text { Demand }\left(\hat{\beta}_{B}^{B}\right)\end{array}$ & $\begin{array}{l}1.38^{* *} \\
(0.36)\end{array}$ & $\begin{array}{l}5.17^{* *} \\
(1.77)\end{array}$ & $\begin{array}{l}4.82^{* *} \\
(1.85)\end{array}$ & $\begin{array}{l}4.53^{*} \\
(1.77)\end{array}$ & $\begin{array}{l}4.49^{* *} \\
(1.81)\end{array}$ \\
\hline $\begin{array}{l}\text { Hispanic Share, Black } \\
\text { Demand }\left(\hat{\beta}_{H}^{B}\right)\end{array}$ & $\begin{array}{l}-0.05 \\
(0.22)\end{array}$ & $\begin{array}{l}3.52^{*} \\
(1.82)\end{array}$ & $\begin{array}{c}3.23 \\
(1.90)\end{array}$ & $\begin{array}{c}3.05 \\
(1.84)\end{array}$ & $\begin{array}{c}2.90 \\
(1.88)\end{array}$ \\
\hline $\begin{array}{l}\text { Black Share, Hispanic } \\
\text { Demand }\left(\hat{\beta}_{B}^{H}\right)\end{array}$ & $\begin{array}{l}1.03^{* *} \\
(0.27)\end{array}$ & $\begin{array}{c}6.03^{* *} \\
(0.82)\end{array}$ & $\begin{array}{l}5.88^{* *} \\
(0.84)\end{array}$ & $\begin{array}{c}5.73^{* *} \\
(0.82)\end{array}$ & $\begin{array}{r}5.89^{* *} \\
(0.82)\end{array}$ \\
\hline $\begin{array}{l}\text { Hispanic Share, Hispanic } \\
\text { Demand }\left(\hat{\beta}_{H}^{H}\right)\end{array}$ & $\begin{array}{l}1.16^{* *} \\
(0.21)\end{array}$ & $\begin{array}{c}6.80^{* *} \\
(0.72)\end{array}$ & $\begin{array}{l}6.67^{* *} \\
(0.76)\end{array}$ & $\begin{array}{l}6.59^{* *} \\
(0.74)\end{array}$ & $\begin{array}{c}6.58^{* *} \\
(0.74)\end{array}$ \\
\hline $\begin{array}{l}\text { Other Private Amenities } \\
\text { Included? }\end{array}$ & No & No & Yes & Yes & Yes \\
\hline $\begin{array}{l}\text { Other Peer } \\
\text { Characteristics } \\
\text { Included? }\end{array}$ & No & No & No & Yes & Yes \\
\hline School Quality Included? & No & No & No & No & Yes \\
\hline $\begin{array}{l}\text { School-Race Fixed } \\
\text { Effects? }\end{array}$ & Yes & Yes & Yes & Yes & Yes \\
\hline Year-Race Fixed Effects? & Yes & Yes & Yes & Yes & Yes \\
\hline Estimation & OLS & 2SLS & 2SLS & $2 \mathrm{SLS}$ & 2SLS \\
\hline$R^{2}$ & 0.98 & 0.98 & 0.98 & 0.98 & 0.98 \\
\hline Number of Observations & 25380 & 25380 & 25380 & 25380 & 25380 \\
\hline
\end{tabular}

Notes: The dependent variable is $\log$ enrollment by race, school and year $\left(\log n_{j t}^{r}\right)$. The coefficient estimates for private amenities and peer characteristics are available on request. Robust standard errors clustered by school and race are provided in parentheses. * - Statistically significant at the $95 \%$ level, ${ }^{* *}$ - Statistically significant at the $99 \%$ level.

Table 7: Comparison of Predictions

\begin{tabular}{lcc}
\hline & $\begin{array}{c}\text { Average Correlation of } \\
S_{j 2006}^{\prime}(s) \text { with respect to } \\
\text { Baseline } S_{j 2006}(s)\end{array}$ & $\begin{array}{c}\text { Average Out of Sample } \\
\text { Prediction Error (Absolute } \\
\text { Value) }\end{array}$ \\
\hline \hline Baseline & 1.000 & 0.064 \\
Nonlinear Demand & 0.795 & 0.075 \\
Two Social Amenities & 0.867 & 0.063 \\
Inelastic Supply & 0.999 & 0.060 \\
\hline
\end{tabular}

Note: We also report for 2006 correlations of the nonlinear demand prediction and two social amenities prediction (0.664), nonlinear demand prediction and inelastic supply prediction (0.793) and two social amenities prediction and inelastic supply prediction (0.868). 
Figure 1: Racial Composition of Enrollment for Two Selected Schools, 1984-2010


Figure 2: Theoretical Illustrations

(a) Tipping Curve

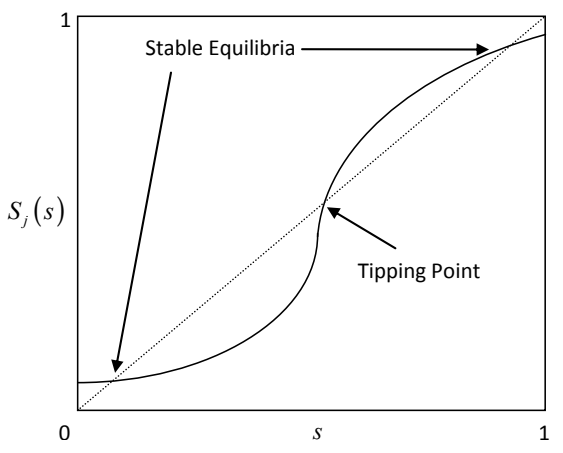

(b) Changing a Private Amenity

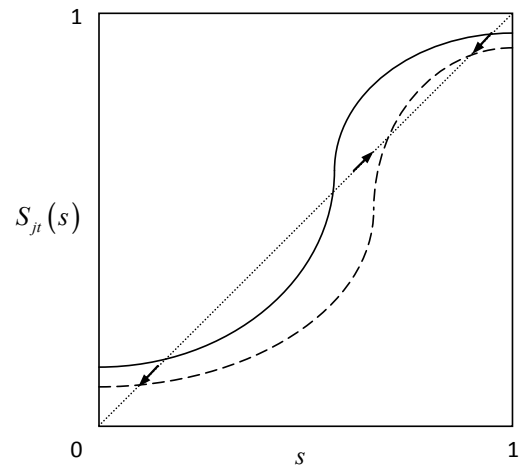

Figure 3: Aggregate Enrollment by Race in Los Angeles County Schools, 1984-2010




Figure 4: Simulated Tipping Behavior for Three Selected Los Angeles County Schools, 2006
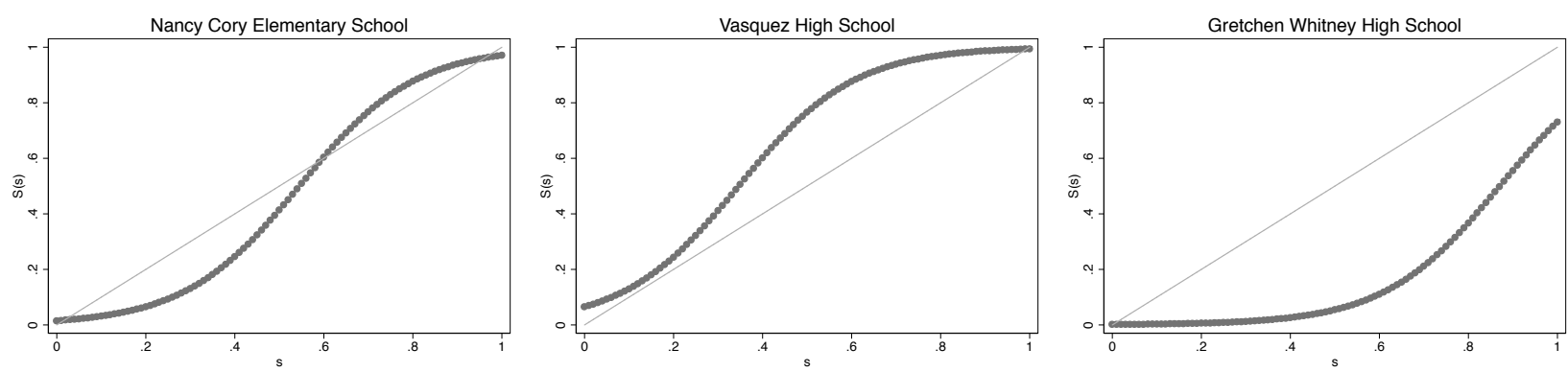

Note: The simulation uses demand estimates from column 2 of table 2 .

Figure 5: Histograms of Tipping Points and Stable Equilibria for All Los Angeles County Schools, 2006: Baseline Demand Specification

(a) Tipping Points

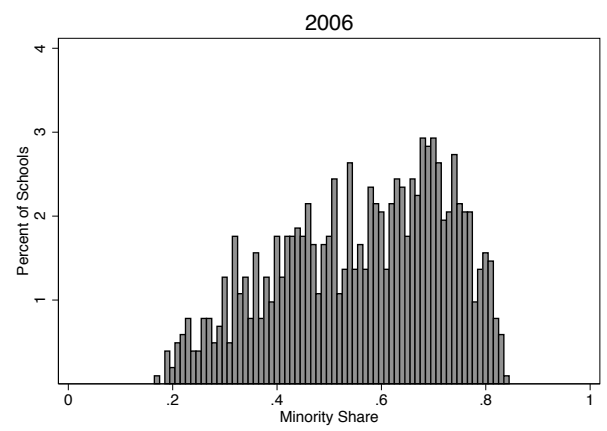

(b) Stable Equilibria

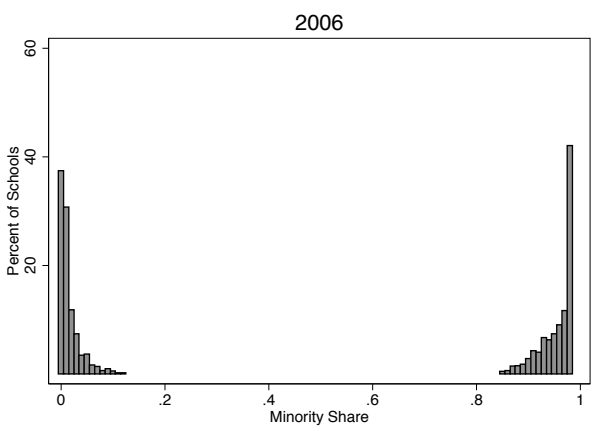

Note: The tipping histogram contains all Los Angeles schools that possess a tipping point.

Figure 6: Simulated Tipping Behavior for Three Selected Los Angeles County Schools, 2006: Flexible Demand Specification
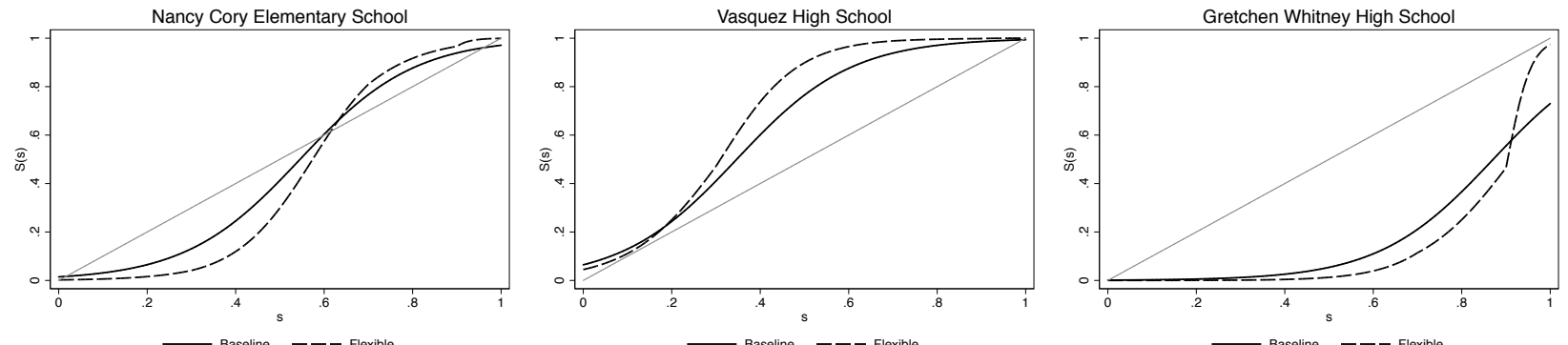

Note: The baseline simulation uses demand estimates from column 2 of table 2. The flexible demand specification uses estimates from column 2 of table 5 . 
Figure 7: Histograms of Tipping Points and Stable Equilibria for All Los Angeles County Schools, 2006: Flexible Demand Specification

(a) Tipping Points

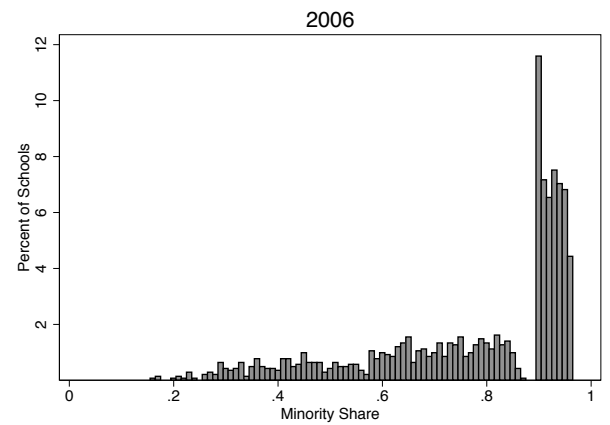

(b) Stable Equilibria

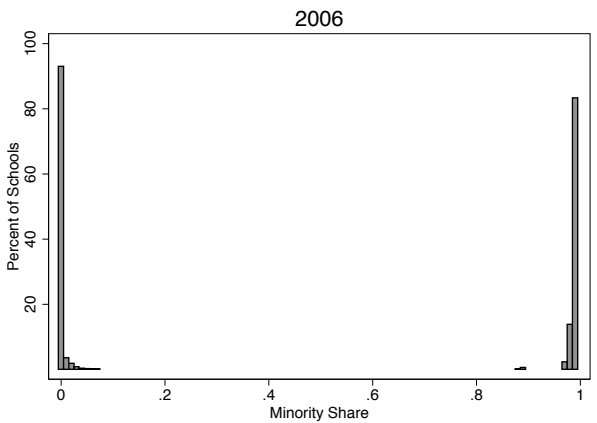

Note: The tipping histogram contains all Los Angeles schools that possess a tipping point.

Figure 8: Simulated Tipping Behavior in Nancy Cory Elementary School, 2006

(a) Implied Black Share

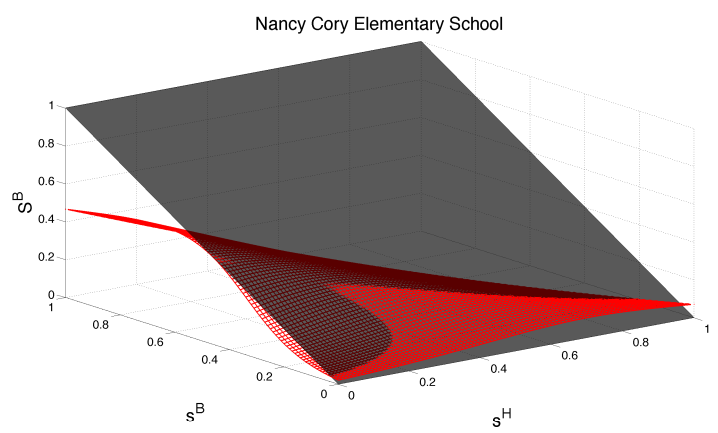

(b) Implied Hispanic Share



Note: The simulation uses demand estimates from column 2 of table 6 .

Figure 9: Contour Diagram for Nancy Cory Elementary School, 2006

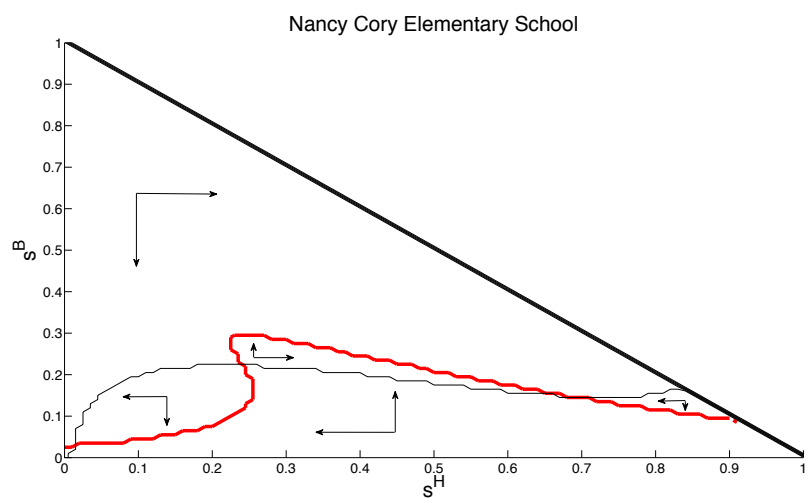


Figure 10: Histograms of Tipping Points and Stable Equilibria for All Los Angeles County Schools, 2006: Two Social Amenities

(a) Tipping Points

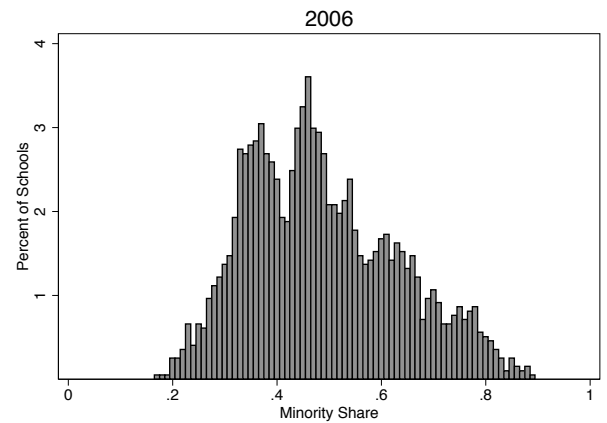

(b) Stable Equilibria



Note: The tipping histogram contains all Los Angeles schools that possess a tipping point.

Figure 11: Simulated Tipping Behavior for Three Selected Los Angeles County Schools, 2006: Inelastic Supply


Note: Both simulated curves use demand estimates from column 2 of table 2.

Figure 12: Histograms of Tipping Points and Stable Equilibria for All Los Angeles County Schools, 2006: Inelastic Supply

(a) Tipping Points

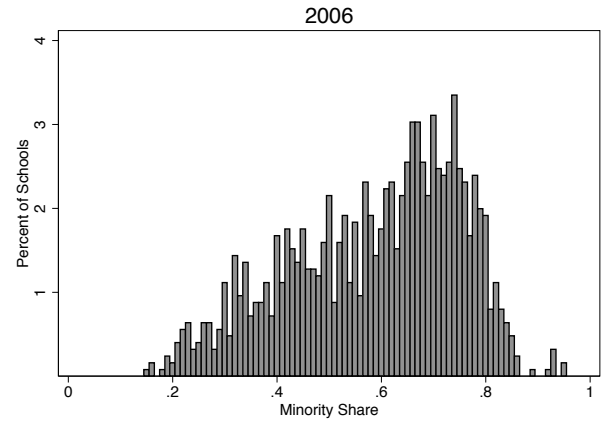

(b) Stable Equilibria

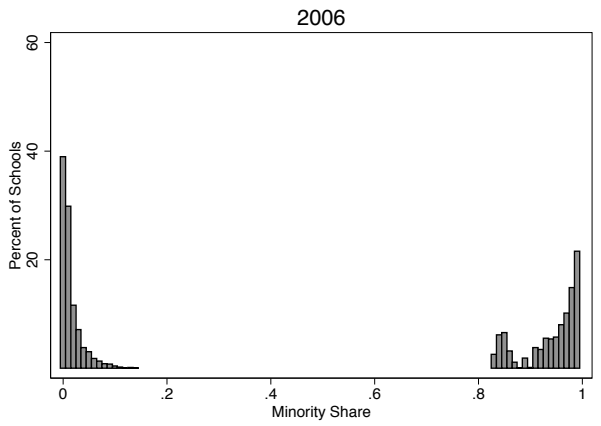

Note: The tipping histogram contains all Los Angeles schools that possess a tipping point. 


\section{A Technical Appendix}

\section{A.1 Discrete Choice Demand Estimation}

In this section we provide micro-foundations to our demand estimation in line with the literature on neighborhood discrete choice models (e.g., Bayer and Timmins (2005), Bayer, Ferreira and McMillan (2007), Caetano (2012)). In each year $t$, parents make a choice of whether to enroll their child in one of $J$ available public schools in Los Angeles County or instead to select the outside option of enrolling their child in a private school or living outside of LA County altogether. We assume that school supply is perfectly elastic. ${ }^{68}$ In addition, we assume that there are no moving costs associated with parent $i$ 's enrollment decision, so it suffices to consider the flow utility of making each choice. ${ }^{69}$

As before, parents make their enrollment decisions in period $t$ having observed school amenities at the end of period $t-1$. We specify the indirect utility of parents of child $i$ of race $r$ enrolled at school $j$ in year $t$ as

$$
U_{i j t}^{r}=\beta^{r} s_{j t-1}+X_{j t-1}^{\prime} \phi^{r}+\xi_{j t}^{r}+\eta_{i j t}^{r}
$$

where all variables and parameters are as described above. $\xi_{j t}^{r}$ represents an unobservable that varies at the school-race-year level, and the error term $\eta_{i j t}^{r}$ is an individual specific unobserved component of utility that is assumed to be i.i.d. extreme value $1 .{ }^{70}$ Each individual chooses among $J+1$ options, where $j=0$ indexes the outside option (interpreted as the choice to send the child to a private school or a public school outside of LA County), and $j=1, \ldots, J$ indexes each public school in LA County.

Parent $i$ of race $r$ chooses school $j$ in year $t$ if

$$
U_{i j t}^{r}>U_{i k t}^{r}
$$

for all alternatives $k \neq j$ including the outside option. We first collect the non-individual specific determinants of utility into $\delta_{j t}^{r} \equiv \delta_{j t}^{r}\left(s_{j t-1}\right)=\beta^{r} s_{j t-1}+X_{j t-1}^{\prime} \phi^{r}+\xi_{j t}^{r}$. We normalize $\delta_{0 t}^{r}=0$ for each $r$ and $t$. It follows from equation (22) that parent $i$ of race $r$ will enroll their child in school $j$ at period $t$ if $\eta_{i k t}^{r}-\eta_{i j t}^{r}<\delta_{j t}^{r}-\delta_{k t}^{r}$ for all $k \neq j$ including the outside option. We denote this probability of enrollment as $P_{i j t}^{r}$. The assumption on the distribution of $\eta$ implies that $P_{i j t}^{r}$ is constant within

\footnotetext{
${ }^{68}$ By modeling the supply side as commonly done in discrete choice demand estimation, one could relax this assumption. See section 5.3 for further details.

${ }^{69}$ With detailed data related to the transition of students between schools, one could relax this assumption and estimate a dynamic discrete choice model (Bayer et al. (2011); Caetano (2012)). See appendix A.2 for a further discussion of this point.

${ }^{70}$ The distribution of $\eta_{i j t}^{r}$ can be generalized following Berry, Levinsohn and Pakes (1995) to account for other types of heterogeneity in preferences.
} 
race, school and year, hence we can drop the subscript $i$ and write this probability as

$$
P_{j t}^{r}\left(s_{j t-1}\right)=\frac{\exp \left(\delta_{j t}^{r}\left(s_{j t-1}\right)\right)}{1+\sum_{k=1}^{J} \exp \left(\delta_{k t}^{r}\left(s_{k t-1}\right)\right)}, \quad j=1, \ldots, J
$$

which is the familiar logit relationship. Following Berry (1994), we can estimate each $\delta_{j t}^{r}$ as

$$
\hat{\delta}_{j t}^{r}=\log \frac{n_{j t}^{r}}{n_{0 t}^{r}}
$$

directly from data. $\hat{\delta}_{j t}^{r}$ can be interpreted as the estimated mean utility that race $r$ parents enjoy from enrolling their children in school $j$ in year $t$. We can then write

$$
\log n_{j t}^{r}=\beta^{r} s_{j t-1}+X_{j t-1}^{\prime} \phi^{r}+\underbrace{\xi_{j t}^{r}+\log n_{0 t}^{r}+\mu_{j t}^{r}}_{\text {unobserved }}, \quad j=1, \ldots, J
$$

where $\mu_{j t}^{r}=\hat{\delta}_{j t}^{r}-\delta_{j t}^{r}$ is the error due to estimation of $\delta$. We can re-write equation (25) as

$$
\log n_{j t}^{r}=\beta^{r} s_{j t-1}+X_{j t-1}^{\prime} \phi^{r}+\gamma_{j}^{r}+\alpha_{t}^{r}+\epsilon_{j t}^{r}, \quad j=1, \ldots, J
$$

where $\gamma_{j}^{r}$ and $\alpha_{t}^{r}$ are school-race fixed effects and year-race fixed effects respectively, and the composite error term $\epsilon_{j t}^{r}=\xi_{j t}^{r}+\log n_{0 t}^{r}+\mu_{j t}^{r}-\gamma_{j}^{r}-\alpha_{t}^{r} \cdot \gamma_{j}^{r}$ absorbs any unobserved component of equation (25) that is school-race specific, and $\alpha_{t}^{r}$ absorbs any unobserved component of equation (25) that is year-race specific. Note that $\alpha_{t}^{r}$ absorbs $\log n_{0 t}^{r}$, which crucially eliminates the need to observe $n_{0 t}^{r}$ (which we do not observe). $\alpha_{t}^{r}$ is identified from the variation in the total number of children of each race attending LA County public schools over time. It follows that $\epsilon_{j t}^{r}$ contains only school-year and school-year-race specific components, which we argue to be orthogonal to the proposed instrument described in section 3. Thus, the reduced form demand estimation procedure outlined in section 3 is equivalent to a standard, well defined school decision problem, and the proposed instrument can be used to identify $\beta^{r}$.

It is also the case that the simulation procedure in this discrete choice framework is equivalent to the simulation procedure described in section 3. Without loss of generality, consider the following decomposition

$$
P_{i j t}^{r}=\pi_{i j t}^{r} \cdot P_{i t}^{r}, \quad j=1, \ldots, J
$$

where $P_{i t}^{r}$ is the probability that a parent $i$ of race $r$ will not choose the outside option, and $\pi_{i j t}^{r}$ is the probability of that parent choosing school $j$ conditional on not choosing the outside option. Given 
our assumptions, we can drop the index $i$ for simplicity and denote this conditional probability $\pi_{j t}^{r}$. Equations (23) and (27) then imply

$$
\pi_{j t}^{r}\left(s_{j t-1}\right)=\frac{\exp \left(\delta_{j t}^{r}\left(s_{j t-1}\right)\right)}{\sum_{k=1}^{J} \exp \left(\delta_{k t}^{r}\left(s_{k t-1}\right)\right)}, \quad j=1, \ldots, J .
$$

For each counterfactual value $s$, the implied share of minority students in school $j$ at time $t, S_{j t}(s)$, can then be written as

$$
S_{j t}(s)=\frac{N_{t}^{M} \pi_{j t}^{M}(s)}{N_{t}^{M} \pi_{j t}^{M}(s)+N_{t}^{W} \pi_{j t}^{W}(s)}, \quad j=1, \ldots, J,
$$

where $N_{t}^{r}=\sum_{k=1}^{J} n_{k t}^{r}$. Substituting equation (24) into equation (28) yields ${ }^{71}$

$$
\begin{aligned}
\pi_{j t}^{r}(s) & =\frac{\exp \left(\log n_{j t}^{r}(s)-\log n_{0 t}^{r}(s)\right)}{\sum_{k=1}^{J} \exp \left(\log n_{k t}^{r}(s)-\log n_{0 t}^{r}(s)\right)} \\
& =\frac{n_{j t}^{r}(s)}{\sum_{k=1}^{J} n_{k t}^{r}(s)}, \quad j=1, \ldots, J .
\end{aligned}
$$

Finally, by substituting (30) into (29), we arrive at equation (6) in the main text. Note that holding $\alpha_{t}^{r}$ fixed in the simulation implicitly assumes that the re-sorting only occurs among parents whose children are attending public schools in LA County already. This is equivalent to having conditioned only on people who had already chosen one of the schools $j=1, \ldots, J$, which provides a stationary environment suitable for the identification of fixed points using the simulation procedure outlined in section 3.

\section{A.2 Further Extensions}

In this appendix, we discuss in detail three further realistic extensions of our framework which are not implemented in the paper for various reasons. Although these extensions have not been performed or even discussed in detail in the literature to the best of our knowledge, we believe that they may be necessary for a more complete analysis of tipping behavior. Our framework can be leveraged to provide a novel detailed discussion about these extensions, thereby advancing our understanding of this topic.

\footnotetext{
${ }^{71}$ Equation $(24)$ can be written more generally as $\delta_{j t}^{r}(s)=\log \frac{n_{j t}^{r}(s)}{n_{0 t}^{r}(s)}$.
} 


\section{A.2.1 Individual Level Data}

We conduct our empirical analysis using school level data as opposed to individual level data. ${ }^{72}$ Our approach could be implemented with individual data allowing parents to have systematically heterogeneous preferences based on race, income, family education, etc. However, estimating this richer substitution pattern involves an important trade-off, as doing so may imply a less useful counterfactual in the simulation exercise. To illustrate, assume that we observe parents' income, and rich, White (and minority) parents have a different preference for the minority share than poor, White (and minority) parents. In this case, controlling for the income of the household in the first stage when estimating $\beta^{r}$ may generate a less useful counterfactual in the simulation stage than not controlling for it. By not controlling for income, we do not hold income constant for each counterfactual value of $s$, so the simulation should be interpreted as allowing the average (in all other characteristics) White or minority student to flow in or out of the school. If Whites tend to be richer than minorities, then the simulation performed in the paper involves a flow of White (and/or minority) students and implicitly allows parents to re-sort using the statistical information that Whites tend to be richer than minorities. If we instead held income constant in the simulation, then we would necessarily be considering flows of White and minority students of equal levels of income. And if we control for more demographic characteristics, such a simulation may not even constitute a feasible reallocation of parents, as there may not be parents of different races and with the same level of all other observable characteristics. Thus, by not controlling for non-racial characteristics of parents when estimating demand (even if individual data was observable), we can conduct a more relevant simulation procedure. Of course, race should then be interpreted as a proxy for the whole bundle of characteristics of a typical student of that race, which is what we explicitly do. This interpretation is in line with the empirical literature on school segregation (e.g., Jackson (2009) and Billings, Deming and Rockoff (2012)).

More generally, we could also use individual level data to add more social amenities to the analysis. Consider for instance the case where we observe demand stratified by race-income. That would allow us to identify $\delta_{j t}^{g}$, where

$$
g \in\{\text { Rich-White,Poor-White,Rich-Minority,Poor-Minority }\}
$$

We would then be able to analyze tipping behavior with respect to three social amenities rather than just one, where the four groups would be allowed to have heterogeneous preferences over these three amenities (as well as the private amenities). We are unable to perform this analysis for lack

\footnotetext{
${ }^{72}$ Individual level student data in the state of California is unavailable in restricted or unrestricted formats. The California Department of Education mentions that "California Standardized Testing and Reporting (STAR) Program test results for schools, counties, districts, and the state are available at this site. (...) Important Note: Test results for individual students are available only to parents/guardians and may be obtained only from the schools and school districts where students were tested. Individual student results are not available on the Internet nor from the California Department of Education." Source: http://star.cde.ca.gov/star2012/index.aspx.
} 
of data, but we do offer an extension of our framework with two social amenities in section 5.2 to illustrate the complex analysis that can be performed with our approach. Although stratifying demand by race-income is likely to provide some interesting insights into tipping behavior, it does come with the same cost related to the plausibility of the counterfactual, as discussed above.

\section{A.2.2 Forward Looking Behavior}

A fundamental assumption of the Schelling model and its successors is the assumption of myopia - i.e., agents do not engage in forward looking behavior. Given our identification strategy, deviations from this assumption are not likely to change our results. Formally, let $s_{j t}^{e}$ be the (unobservable) expected minority share in school $j$ just before parents make their decision in period $t$ assuming they are forward looking agents. If parents are forward looking, then we can express the error in our specification as $M E_{j t} \equiv s_{j t}^{e}-s_{j t-1} \neq 0$. We can then rewrite equation (2) in the paper as

$$
\log n_{j t}^{r}=\beta^{r} s_{j t-1}+X_{j t-1}^{\prime} \phi^{r}+\gamma_{j}^{r}+\alpha_{t}^{r}+\tilde{\epsilon}_{j t}^{r}
$$

where $\tilde{\epsilon}_{j t}^{r}=\epsilon_{j t}^{r}+\beta^{r} M E_{j t}$ and $\epsilon_{j t}^{r}$ is the regression error with myopia. First, note that only the component of $\beta^{r} M E_{j t}$ that is school-year and school-year-race specific will not be absorbed by the fixed effects. Second, the IV will be uncorrelated to $\tilde{\epsilon}_{j t}^{r}$ as long as the transitory county-wide shock in $t-1$ that affects entry into LA County public schools (i.e., $N_{t-1}^{r}$ ) is uncorrelated to school-specific shocks just before period $t$ that affect entry into $j$ (i.e., $\tilde{\epsilon}_{j t}^{r}$ ). Hence, the argument for the validity of the IV is exactly the same as before. Intuitively, our IV explores exogenous variation in $s_{j t}^{e}$ through $s_{j t-1}$ only.

\section{A.2.3 Moving Costs}

In our empirical analysis, we assume that parents do not bear moving costs when switching schools. Because individual level data in LA County is unavailable, we cannot observe students switching schools, and this makes the identification of moving costs impossible. ${ }^{73}$ Nevertheless, we can still explore how the zero moving cost assumption affects our analysis. Consider (in the notation

of appendix A.1) $\mu_{j t}^{r}=\delta_{j t}^{r}-\hat{\delta}_{j t}^{r} \neq 0$, which is the measurement error due to the estimation of a static discrete choice model when the true model is dynamic with moving costs. By construction, $\delta_{j t}^{r}$ is the true average choice-specific value function for school $j$, race $r$ and period $t$, which is not only a function of the amenities of school $j$ in period $t$ but also a function of expected future amenities in all schools weighted by the likelihood of the household transitioning from $j$ to any particular school in the future. Our IV will address this new measurement error under the same validity argument: as long as the transitory county-wide shock in $t-1$ that affects entry into LA County public schools

\footnotetext{
${ }^{73}$ Even with this data, estimation of such dynamic discrete choice models is difficult to implement because the state space is too large. Only recently have methods to feasibly estimate such models been developed, and they either require additional data (Bayer et al. (2011)) or assumptions of stationarity (Caetano (2012)).
} 
(i.e., $N_{t-1}^{r}$ ) is uncorrelated to school-specific shocks just before period $t$ that affect entry into $j$ (i.e., $\epsilon_{j t}^{r}$ ). Of course, a component of the school-specific shocks to $j$ may be now (in the presence of moving costs) related to expected future school-specific shocks of school $j$ or of other schools $k \neq j$, but the validity argument is exactly the same.

Even though assuming zero moving costs is not likely to affect the causal estimates in the first stage, it may still affect the simulation procedure in the second stage. When we allow students to re-sort for each counterfactual value of $s$, we need to take into account that students will be less likely to re-sort if they would have to incur in moving costs to do so. However, the tipping points as well as the stable equilibria will be the same as the ones we found under the assumption of no moving costs. To see this, note that $|\tilde{S}(s)-s| \leq|S(s)-s|$, where $S(\cdot)$ is the curve as estimated in the paper and $\tilde{S}(\cdot)$ is the curve in the presence of moving costs. ${ }^{74}$ This inequality holds because moving costs act as an additional friction that may prevent some students from moving from their original location, where $s_{j t-1}=s$. Any equilibrium (stable or unstable) has the property that $\tilde{S}(s)=s$ in the presence of moving costs. Thus, the inequality above implies that the values of $s$ that we found in the paper to be equilibria (i.e., $S(s)=s$ ) will necessarily be also equilibria in the presence of moving costs. ${ }^{75}$

\footnotetext{
${ }^{74}$ Graphically, this inequality implies that the $\tilde{S}(\cdot)$ curve is no farther from the 45 degree line than the $S(\cdot)$ curve at any point in the domain.

${ }^{75}$ The converse is not necessarily true. For large enough levels of moving costs, the true curve may contain more equilibria than we find under the assumption of zero moving costs. In the limit, as moving costs go to infinity, the true curve will coincide with the 45 degree straight line implying an infinite number of equilibria.
} 


\section{B For Online Publication: Auxiliary Tables and Figures}

Table B.1: Full Parameter Estimates for Baseline Specification

\begin{tabular}{|c|c|c|c|c|c|c|}
\hline \multirow[b]{2}{*}{ Variable } & \multicolumn{2}{|c|}{ (3) } & \multicolumn{2}{|c|}{$(4)$} & \multicolumn{2}{|c|}{ (5) } \\
\hline & W & M & W & M & W & M \\
\hline Minority Share & $\begin{array}{l}-1.91 \\
(1.39)\end{array}$ & $\begin{array}{c}5.74^{* *} \\
(0.57)\end{array}$ & $\begin{array}{l}-2.00 \\
(1.36)\end{array}$ & $\begin{array}{c}5.70^{* *} \\
(0.56)\end{array}$ & $\begin{array}{l}-2.44 \\
(1.42)\end{array}$ & $\begin{array}{c}5.70^{* *} \\
(0.58)\end{array}$ \\
\hline $\begin{array}{l}\text { Full Time Equivalent } \\
\text { Teachers per Student }\end{array}$ & $\begin{array}{l}-0.47 \\
(0.58)\end{array}$ & $\begin{array}{l}-1.09 \\
(0.30)\end{array}$ & $\begin{array}{l}-0.47 \\
(0.59)\end{array}$ & $\begin{array}{c}-1.10^{* *} \\
(0.30)\end{array}$ & $\begin{array}{l}-0.42 \\
(0.59)\end{array}$ & $\begin{array}{c}-1.10^{* *} \\
(0.29)\end{array}$ \\
\hline $\begin{array}{l}\text { Share of Teachers with a } \\
\text { Bachelor's Degree }\end{array}$ & $\begin{array}{l}-0.16 \\
(0.11)\end{array}$ & $\begin{array}{c}0.06 \\
(0.06)\end{array}$ & $\begin{array}{l}-0.16 \\
(0.11)\end{array}$ & $\begin{array}{c}0.07 \\
(0.06)\end{array}$ & $\begin{array}{l}-0.13 \\
(0.11)\end{array}$ & $\begin{array}{c}0.07 \\
(0.06)\end{array}$ \\
\hline $\begin{array}{l}\text { Share of Teachers with a } \\
\text { Master's Degree }\end{array}$ & $\begin{array}{c}-0.24^{* *} \\
(0.08)\end{array}$ & $\begin{array}{c}0.06 \\
(0.05)\end{array}$ & $\begin{array}{c}-0.25^{* *} \\
(0.08)\end{array}$ & $\begin{array}{l}-0.06 \\
(0.05)\end{array}$ & $\begin{array}{c}-0.23^{* *} \\
(0.08)\end{array}$ & $\begin{array}{l}-0.06 \\
(0.05)\end{array}$ \\
\hline $\begin{array}{l}\text { Share of Teachers who are } \\
\text { Minorities }\end{array}$ & $\begin{array}{c}0.01 \\
(0.11)\end{array}$ & $\begin{array}{c}0.01 \\
(0.06)\end{array}$ & $\begin{array}{c}0.01 \\
(0.11)\end{array}$ & $\begin{array}{c}0.01 \\
(0.06)\end{array}$ & $\begin{array}{c}0.02 \\
(0.11)\end{array}$ & $\begin{array}{c}0.01 \\
(0.06)\end{array}$ \\
\hline Computers per Student & $\begin{array}{c}-0.08 * * \\
(0.03)\end{array}$ & $\begin{array}{l}-0.02 \\
(0.03)\end{array}$ & $\begin{array}{c}-0.08^{* *} \\
(0.03)\end{array}$ & $\begin{array}{l}-0.02 \\
(0.03)\end{array}$ & $\begin{array}{c}-0.08^{* *} \\
(0.03)\end{array}$ & $\begin{array}{l}-0.02 \\
(0.03)\end{array}$ \\
\hline $\begin{array}{l}\text { Internet Connected } \\
\text { Computers per Student }\end{array}$ & $\begin{array}{c}0.14 \\
(0.14)\end{array}$ & $\begin{array}{l}-0.07 \\
(0.09)\end{array}$ & $\begin{array}{c}0.15 \\
(0.14)\end{array}$ & $\begin{array}{l}-0.07 \\
(0.09)\end{array}$ & $\begin{array}{c}0.15 \\
(0.14)\end{array}$ & $\begin{array}{l}-0.07 \\
(0.09)\end{array}$ \\
\hline $\begin{array}{l}\text { Number of Staff Providing } \\
\text { English Learning Services } \\
\text { to Spanish Speakers per } \\
\text { Student }\end{array}$ & $\begin{array}{c}0.82 \\
(1.06)\end{array}$ & $\begin{array}{c}0.23 \\
(0.44)\end{array}$ & $\begin{array}{c}0.96 \\
(1.06)\end{array}$ & $\begin{array}{c}0.24 \\
(0.43)\end{array}$ & $\begin{array}{l}1.12 \\
(1.05)\end{array}$ & $\begin{array}{c}0.24 \\
(0.43)\end{array}$ \\
\hline $\begin{array}{l}=1 \text { if school operates on a } \\
\text { traditional } 9 \text { month } \\
\text { calendar }\end{array}$ & $\begin{array}{l}-0.01 \\
(0.03)\end{array}$ & $\begin{array}{c}-0.07^{* *} \\
(0.01)\end{array}$ & $\begin{array}{l}-0.01 \\
(0.03)\end{array}$ & $\begin{array}{c}-0.07^{* *} \\
(0.01)\end{array}$ & $\begin{array}{c}0.00 \\
(0.03)\end{array}$ & $\begin{array}{c}-0.07^{* *} \\
(0.02)\end{array}$ \\
\hline $\begin{array}{l}\text { Share of Students Eligible } \\
\text { for Free or Reduced Price } \\
\text { Lunch }\end{array}$ & - & - & $\begin{array}{c}0.07 \\
(0.08)\end{array}$ & $\begin{array}{c}-0.12^{* *} \\
(0.05)\end{array}$ & $\begin{array}{c}0.10 \\
(0.08)\end{array}$ & $\begin{array}{c}-0.12^{* *} \\
(0.05)\end{array}$ \\
\hline $\begin{array}{l}\text { Share of Students with } \\
\text { Parent with Some College }\end{array}$ & - & - & $\begin{array}{c}0.04 \\
(0.06)\end{array}$ & $\begin{array}{c}0.04 \\
(0.03)\end{array}$ & $\begin{array}{c}0.05 \\
(0.06)\end{array}$ & $\begin{array}{c}0.04 \\
(0.03)\end{array}$ \\
\hline API & - & - & - & - & $\begin{array}{c}-0.00 \\
(0.00)\end{array}$ & $\begin{array}{c}-0.00 \\
(0.00)\end{array}$ \\
\hline School-Race Fixed Effects? & \multicolumn{2}{|c|}{ Yes } & \multicolumn{2}{|c|}{ Yes } & \multicolumn{2}{|c|}{ Yes } \\
\hline Year-Race Fixed Effects? & \multicolumn{2}{|c|}{ Yes } & \multicolumn{2}{|c|}{ Yes } & \multicolumn{2}{|c|}{ Yes } \\
\hline$R^{2}$ & \multicolumn{2}{|c|}{0.98} & \multicolumn{2}{|c|}{0.98} & \multicolumn{2}{|c|}{0.98} \\
\hline Number of Observations & \multicolumn{2}{|c|}{16920} & \multicolumn{2}{|c|}{16920} & \multicolumn{2}{|c|}{16920} \\
\hline
\end{tabular}

Notes: The dependent variable is log enrollment by race, school and year $\left(\log n_{j t}^{r}\right)$. Robust standard errors clustered by school and race are provided in parentheses.

* - Statistically significant at the $95 \%$ level, ** - Statistically significant at the $99 \%$ level. 
Table B.2: First Stage Parameter Estimates for Baseline Specification

\begin{tabular}{lcccc}
\hline Variable & $(2)$ & $(3)$ & $(4)$ & $(5)$ \\
\hline$z_{j t-1}$ & $1.36^{* *}$ & $1.32^{* *}$ & $1.36^{* *}$ & $1.32^{* *}$ \\
& $(0.18)$ & $(0.18)$ & $(0.17)$ & $(0.17)$ \\
$\begin{array}{l}\text { Other School Amenities } \\
\text { Included? }\end{array}$ & No & Yes & Yes & Yes \\
Other Peer Characteristics & No & No & Yes & Yes \\
Included? & No & No & No & Yes \\
School Quality Included? & Yes & Yes & Yes & Yes \\
School-Race Fixed Effects? & Yes & Yes & Yes & Yes \\
Year-Race Fixed Effects? & 0.99 & 0.99 & 0.99 & 0.99 \\
\hline$R^{2}$ & 16920 & 16920 & 16920 & 16920 \\
Number of Observations & is & & & \\
\hline
\end{tabular}

Notes: The dependent variable in each column is the minority share for each school and year $\left(s_{j t}\right)$. Robust standard errors clustered by school and race are provided in parentheses. Coefficient estimates for other included variables are available from the authors upon request. * - Statistically significant at the $95 \%$ level, ** - Statistically significant at the $99 \%$ level.

Table B.3: Prevalence of Tipping Points and Stable Equilibria: Baseline Demand Specification

\begin{tabular}{lccccc}
\hline & 2002 & 2003 & 2004 & 2005 & 2006 \\
\hline \hline $\begin{array}{l}\text { Share of Schools With Tipping } \\
\text { Points }\end{array}$ & 0.64 & 0.63 & 0.63 & 0.61 & 0.61 \\
$\begin{array}{l}\text { Share of Schools with a Stable } \\
\text { White Equilibrium }\left(s^{\star \star}<.5\right)\end{array}$ & 0.83 & 0.83 & 0.82 & 0.82 & 0.83 \\
$\begin{array}{l}\text { Share of Schools with a Stable } \\
\text { Minority Equilibrium }\left(s^{\star \star} \geq .5\right)\end{array}$ & 0.81 & 0.80 & 0.81 & 0.80 & 0.78 \\
\hline
\end{tabular}

Table B.4: Prevalence of Tipping Points and Stable Equilibria: Flexible Demand Specification

\begin{tabular}{lccccc}
\hline & 2002 & 2003 & 2004 & 2005 & 2006 \\
\hline \hline $\begin{array}{l}\text { Share of Schools With Tipping } \\
\text { Points }\end{array}$ & 0.88 & 0.88 & 0.88 & 0.88 & 0.84 \\
$\begin{array}{l}\text { Share of Schools with a Stable } \\
\text { White Equilibrium }\left(s^{\star \star}<0.5\right)\end{array}$ & 0.99 & 0.99 & 0.99 & 0.99 & 0.99 \\
$\begin{array}{l}\text { Share of Schools with a Stable } \\
\text { Minority Equilibrium }\left(s^{\star \star} \geq 0.5\right)\end{array}$ & 0.88 & 0.89 & 0.88 & 0.88 & 0.85 \\
\hline
\end{tabular}


Table B.5: Prevalence of Tipping Points and Stable Equilibria: Two Social Amenities

\begin{tabular}{lccccc}
\hline & 2002 & 2003 & 2004 & 2005 & 2006 \\
\hline \hline $\begin{array}{l}\text { Share of Schools With Tipping } \\
\text { Points }\end{array}$ & 0.33 & 0.33 & 0.32 & 0.31 & 0.34 \\
$\begin{array}{l}\text { Share of Schools with a Stable } \\
\text { White Equilibrium }\end{array}$ & 0.43 & 0.43 & 0.42 & 0.42 & 0.44 \\
$\left(s^{B \star \star}+s^{H \star \star}<0.5\right)$ & & & & & \\
$\begin{array}{l}\text { Share of Schools with a Stable } \\
\text { Minority Equilibrium } \\
\left(s^{B \star \star}+s^{H \star \star} \geq 0.5\right)\end{array}$ & 0.94 & 0.94 & 0.95 & 0.94 & 0.94 \\
\hline
\end{tabular}

Table B.6: Prevalence of Tipping Points and Stable Equilibria: Inelastic Supply

\begin{tabular}{lccccc}
\hline & 2002 & 2003 & 2004 & 2005 & 2006 \\
\hline \hline $\begin{array}{l}\text { Share of Schools With Tipping } \\
\text { Points }\end{array}$ & 0.75 & 0.75 & 0.74 & 0.74 & 0.74 \\
$\begin{array}{l}\text { Share of Schools with a Stable } \\
\text { White Equilibrium }\left(s^{\star \star}<0.5\right)\end{array}$ & 0.82 & 0.83 & 0.82 & 0.82 & 0.83 \\
$\begin{array}{l}\text { Share of Schools with a Stable } \\
\text { Minority Equilibrium }\left(s^{\star \star} \geq 0.5\right)\end{array}$ & 0.87 & 0.87 & 0.87 & 0.88 & 0.86 \\
\hline
\end{tabular}

Figure B.1: Histogram of Observed Minority Share in Los Angeles Schools, 2006

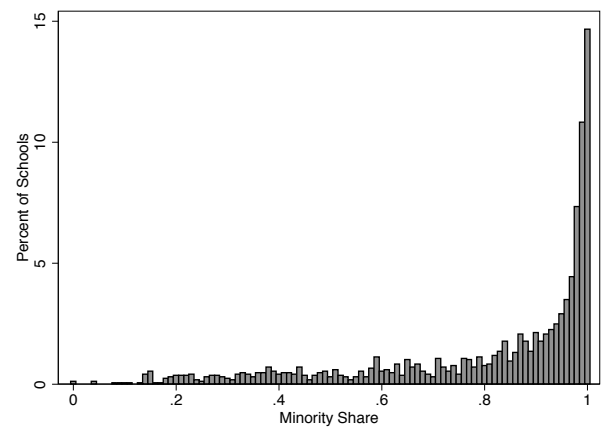


Figure B.2: Histograms of Tipping Points for Los Angeles County Schools, 2002-2005: Baseline Demand Specification
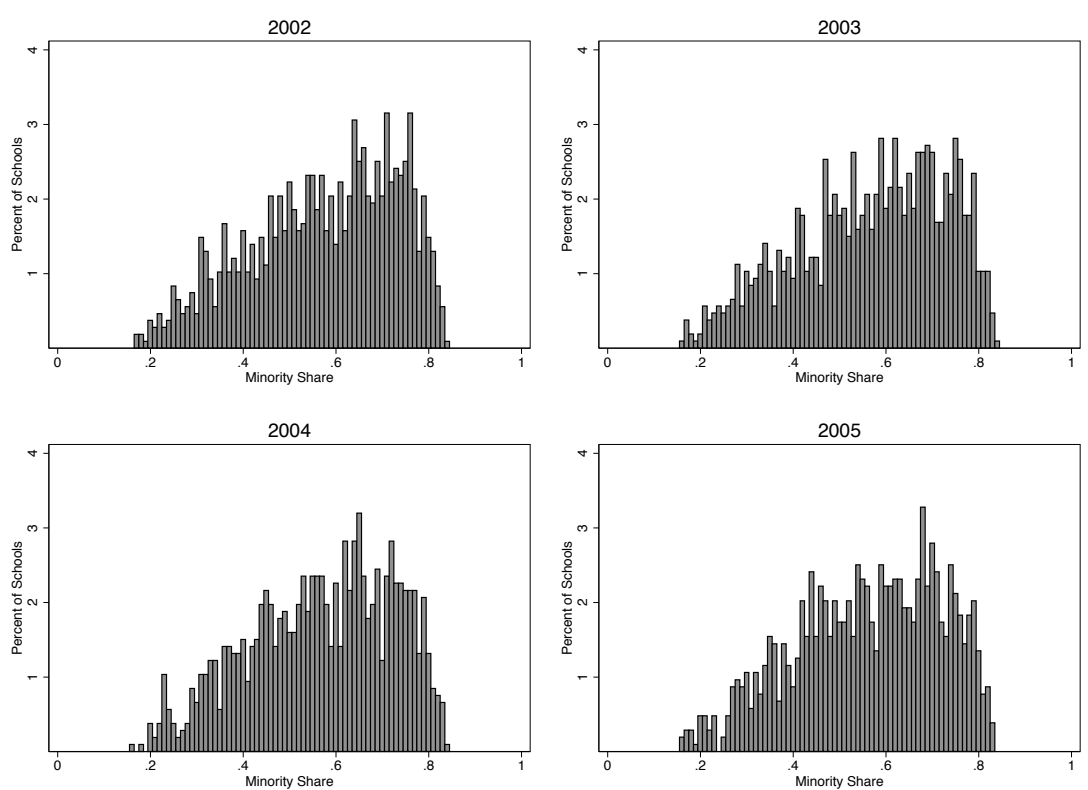

Note: Contains all Los Angeles schools that possess a tipping point.

Figure B.3: Histograms of Stable Equilibria for Los Angeles County Schools, 2002-2005: Baseline Demand Specification
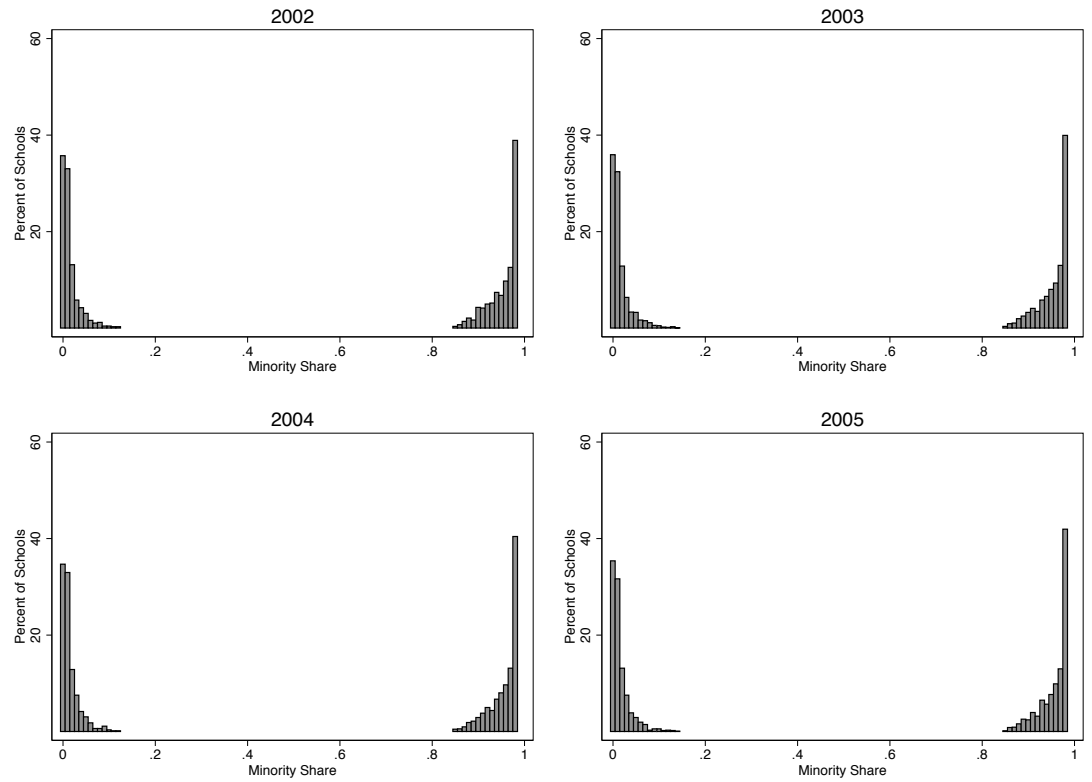
Figure B.4: Histograms of Tipping Points for Los Angeles County Schools, 2002-2005: Flexible Demand Specification
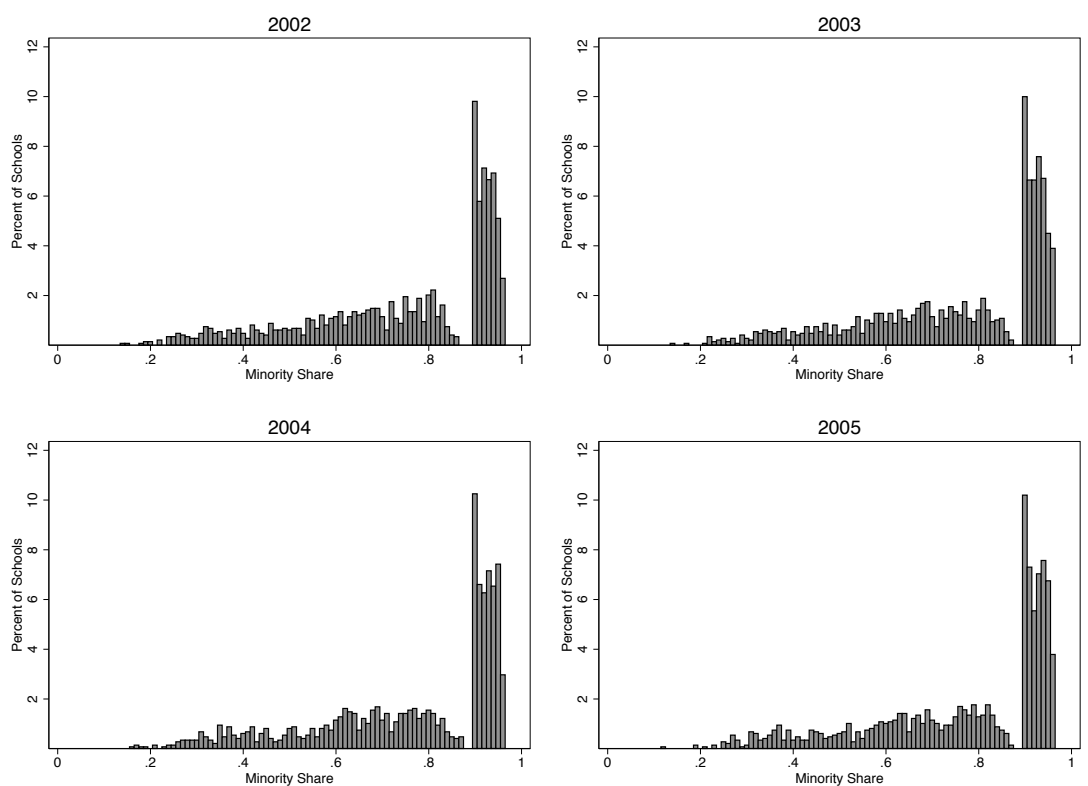

Note: Contains all Los Angeles schools that possess a tipping point.

Figure B.5: Histograms of Stable Equilibria for Los Angeles County Schools, 2002-2005: Flexible Demand Specification
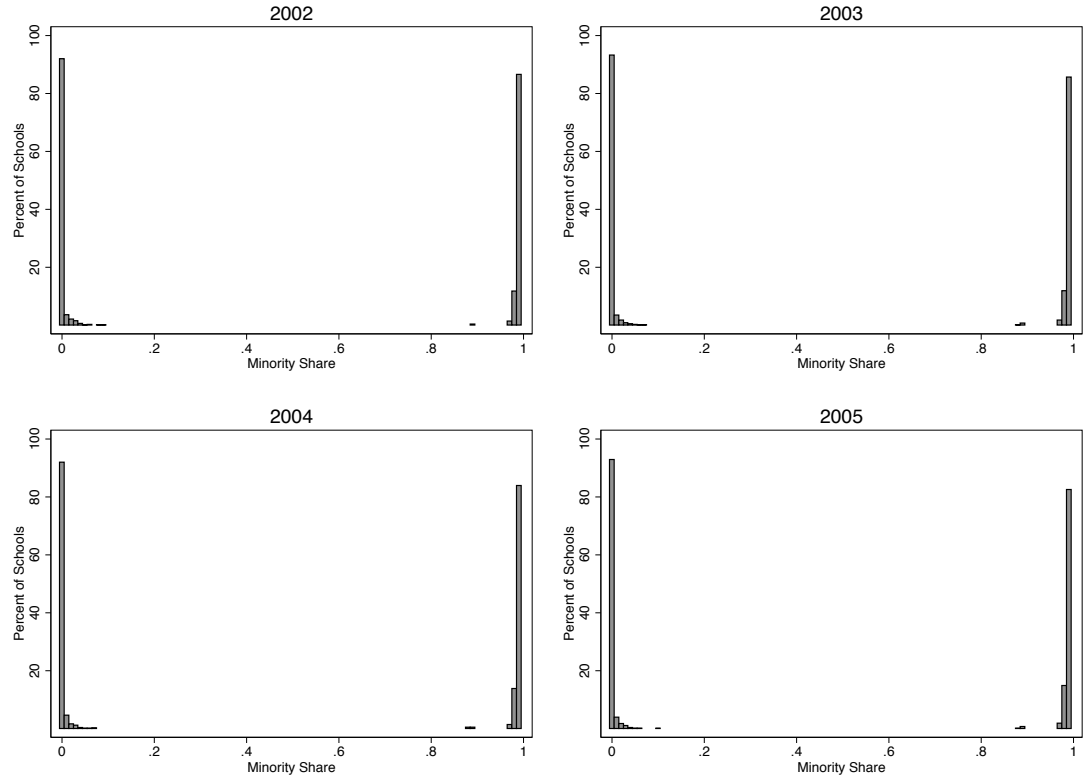
Figure B.6: Histograms of Tipping Points for Los Angeles County Schools, 2002-2005: Two Social Amenities
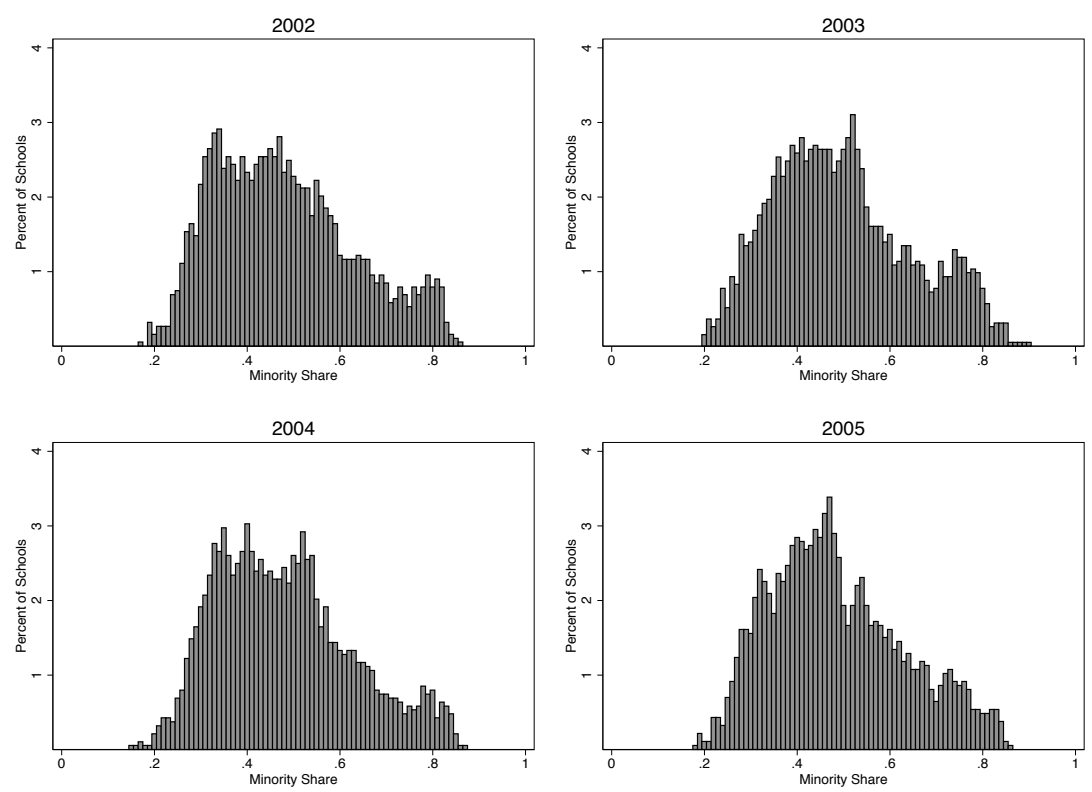

Note: Contains all Los Angeles schools that possess a tipping point.

Figure B.7: Histograms of Stable Equilibria for Los Angeles County Schools, 2002-2005: Two Social Amenities
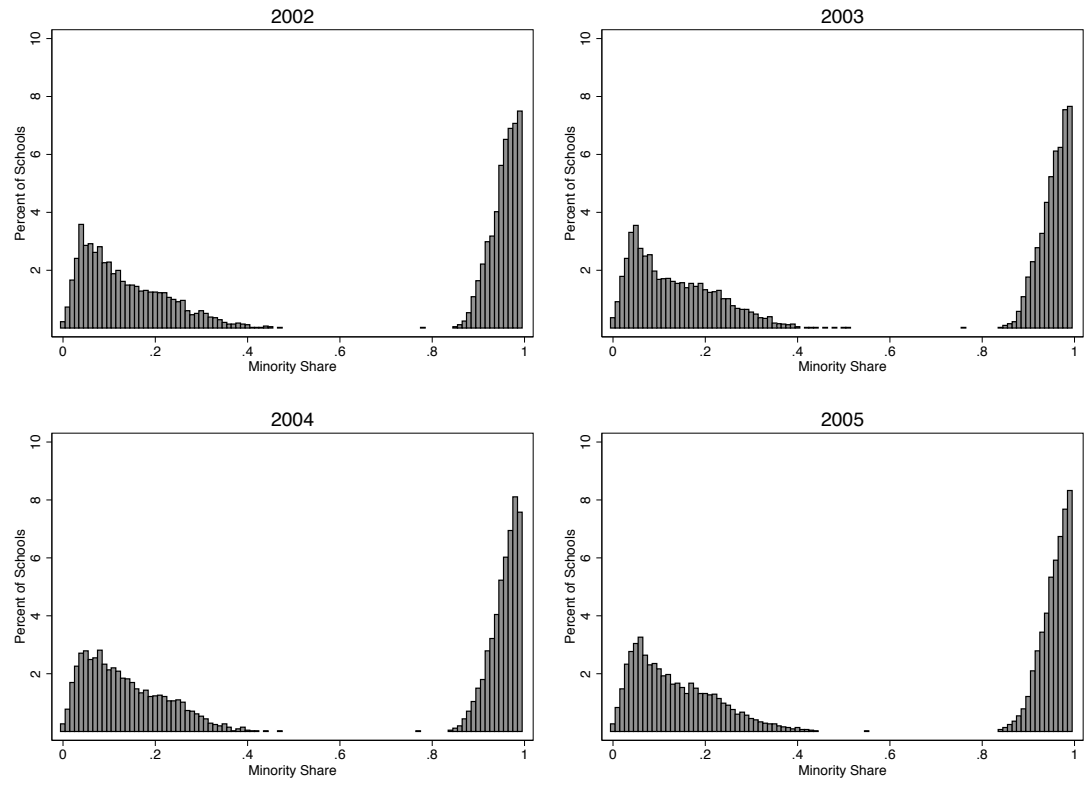
Figure B.8: Histograms of Tipping Points for Los Angeles County Schools, 2002-2005: Inelastic Supply
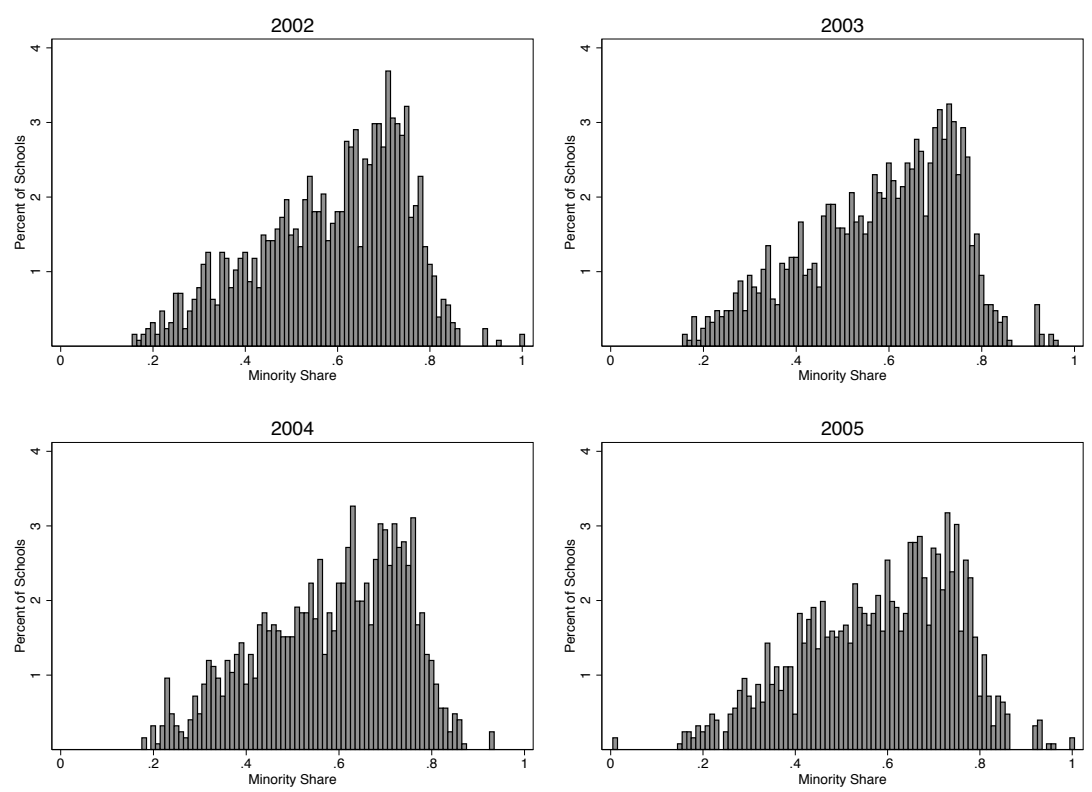

Note: Contains all Los Angeles schools that possess a tipping point.

Figure B.9: Histograms of Stable Equilibria for Los Angeles County Schools, 2002-2005: Inelastic Supply
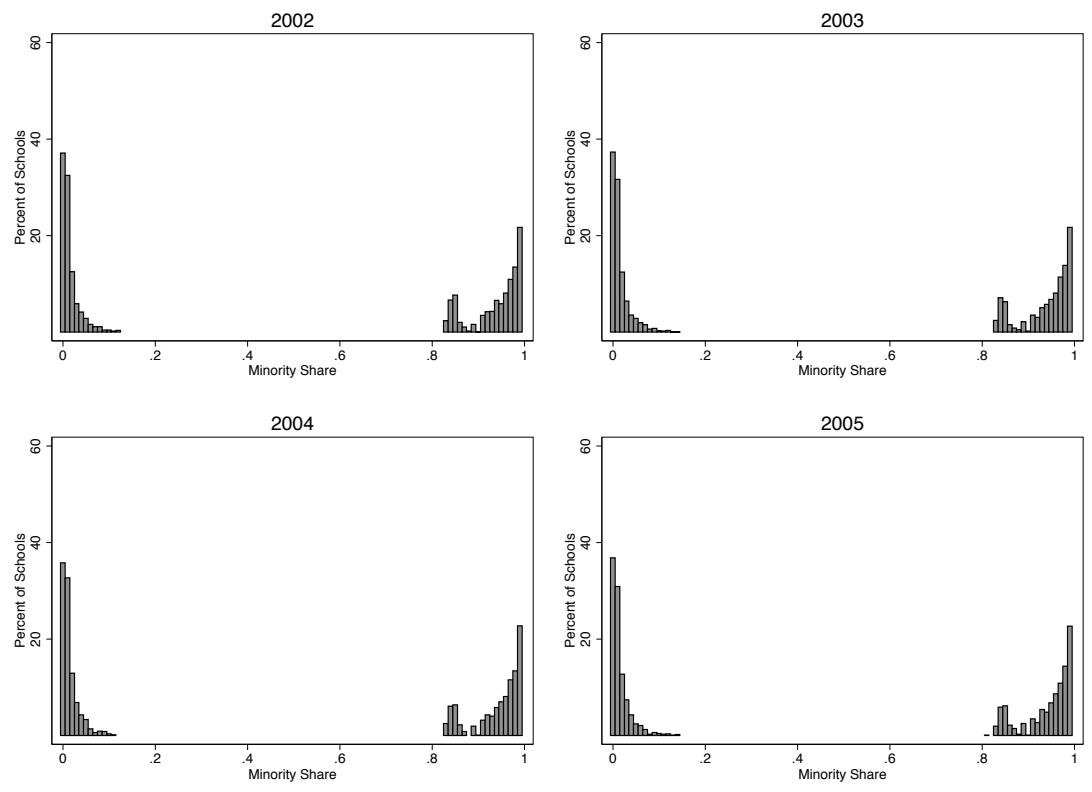
Figure B.10: Out of Sample Prediction Errors Across Specifications
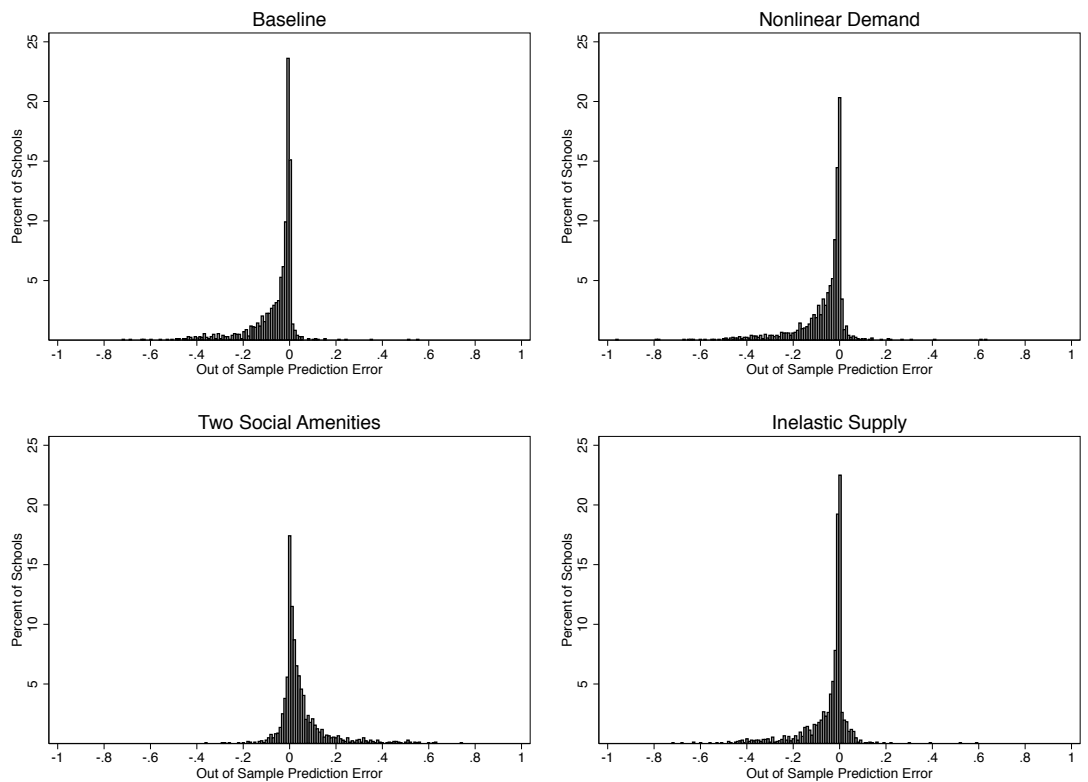

Note: The out of sample prediction error $\left(\sigma_{j}\right)$ is defined in equation (20). 